
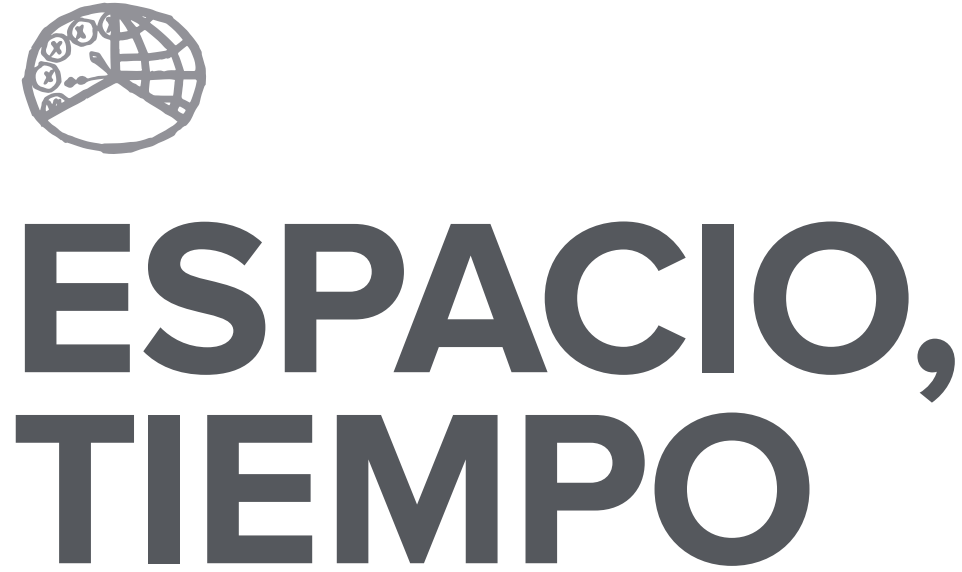

AÑO 2019

ISSN 0214-9745

E-ISSN 2340-1362
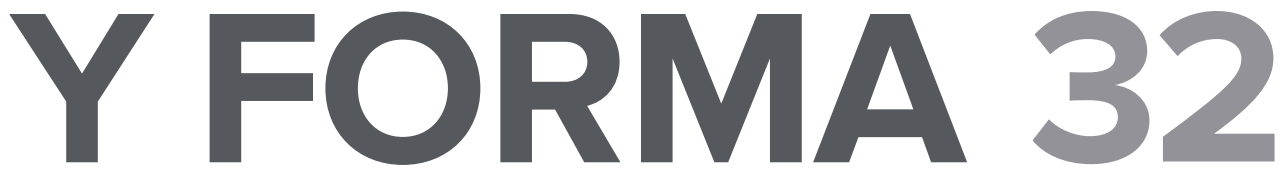

SERIE III HISTORIA MEDIEVAL

REVISTA DE LA FACULTAD DE GEOGRAFÍA E HISTORIA

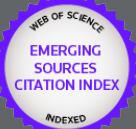





\section{ARTÍCULOS · ARTICLES}





\title{
EL ARCHIVO DEL MONASTERIO CISTERCIENSE DE NUESTRA SEÑORA DE BELMONTE (ASTURIAS, ESPAÑA) EN VÍSPERAS DE LA REFORMA (1560)
}

\section{THE ARCHIVE OF THE CISTERCIAN MONASTERY OF BELMONTE (ASTURIAS, SPAIN) ON THE EVE OF THE REFORMATION (1560)}

\author{
Guillermo Fernández Ortiz \\ Recepción: 2018/05/13. · Comunicación de observaciones de evaluadores: 2018/06/01 . \\ Aceptación: 2019/01/08 \\ DOI: http://dx.doi.org/10.5944/etfiii.32.2019.22057
}

\section{Resumen}

Con la llegada de la Edad Moderna, los monasterios cistercienses de la Corona de Castilla fueron sometidos a un proceso de reforma. Uno de los elementos en el que los reformadores fijaron su atención fue el archivo. En Belmonte, la imagen que se da de él es la de un fondo desarticulado. En el presente artículo se trata de demostrar cómo esa probable desorganización estaba motivada por acontecimientos recientes y no era consecuencia de un desinterés estructural. De este modo, se lleva a cabo el estudio del archivo del monasterio cisterciense de Belmonte antes de 1560 . Se realiza un recorrido por los principales procesos de producción, conservación y refacción documental y se atiende a las prácticas archivísticas desarrolladas por los monjes en la Edad Media y los primeros años de la Edad Moderna.

\section{Palabras clave}

Paleografía y Diplomática; Archivística ; cistercienses ; monasterio de Belmonte.

\section{Abstract}

In the Early Modern Age, the Cistercian monasteries of the Crown of Castile were obliged to undergo a reformation process. The reformers paid special attention to the archives. The image that prevails for the Belmonte monastery is one of a

1. Universidad de Oviedo. C.e.: fernandezguillermo@uniovi.es 
disorganized archive. This article aims to demonstrate that this purported disorganization was induced by recent events of this period rather than caused by systematic neglect. We will focus on Belmonte's archive since its origins in the Middle Ages until 1560. We will examine the main process of production, conservation and diplomatic rewriting, as well as the archival practices applied in Belmonte during the Middle and Early Modern Ages.

\section{Keywords}

Paleography and Diplomatics; Archival Sciences; Cistercian Monks; Monastery of Belmonte. 
Fray Bernardo Escudero, religioso formado en el claustro del monasterio de Valbuena de Duero², llegó a Santa María de Belmonte en I58I para regir los destinos de la abadía asturiana y modernizar los usos administrativos de una casa que aún no se había adaptado a las exigencias de los monjes reformadores de la Congregación cisterciense de Castilla. Entonces encontró una de las causas de su decadencia en el estado de su archivo, lamentando que «casi todas las escripturas deste devoto monasterio (...) an estado en los tiempos passados muy rebueltas y mal puestas y de mala manera» ${ }^{3}$. Sin embargo, y con no ser tal afirmación inexacta, cabe decir que no hace justicia a las atenciones que sus precedesores en el sillón abacial tuvieron con el archivo de la institución.

En las páginas siguientes trataremos de ver cómo, en el Medievo, los monjes no descuidaron el archivo y cómo la imagen de abandono ofrecida por el padre Escudero debía más al duro proceso de incorporación a la Observancia cisterciense castellana que al trato que los monjes de Belmonte dieron a sus documentos durante siglos.

\section{LA GÉNESIS DEL ARCHIVO MEDIEVAL}

\section{I.1. LOS PROCESOS DE ACUMULACIÓN DOCUMENTAL}

La comunidad del monasterio de Belmonte, como la del resto de centros eclesiásticos de su tiempo, y al igual que las demás instituciones del Occidente medieval, procuró poner por escrito sus vínculos contractuales.

Antes de la llegada de los monjes benedictinos a mediados del siglo xil, Belmonte no era más que una de las muchas iglesias en régimen de herederos de la

2. El monasterio de Valbuena de Duero gozaba entonces de una posición de preeminencia en el conjunto de abadías de la Congregación que perdería tiempo después. Para una relación de los hijos de la abadía que llegaron a ser generales de la Oservancia cisterciense castellana vide Archivo Histórico Nacional (AHN). Sección Clero. Regular. Cistercienses. Valbuena de Duero. Legajo 7658. «Tabla de los reverendísimos padres generales que han salido de este Real monasterio de Nuestra Señora Santa María de Valbuena de Duero, en la Congregación de los reynos de la Corona de Castilla, del orden de Nuestro padre San Bernardo, que tubo principio el año de 1427». Entre 1547 y 1575, coincidiendo con la incorporación de Belmonte, cuatro profesos de Valbuena llegaron al generalato (fol. 3v. ${ }^{\circ}$ ).

3. «Casi todas las escripturas deste devoto monasterio de Nuestra Señora de Belmonte, de la Orden de Nuestro Glorioso padre Sant Bernardo, an estado en los tiempos passados muy rebueltas y mal puestas y de mala manera, y porque también esto era causa de que muy raras vezes se leyessen y, de no leerlas, resultava aver muy poca noticia de la hazienda de la casa, y aún ignorancia de mucha della, y que, si en esto no se ponía remedio, sería possible venirse a perder poco a poco lo mucho que los reyes y los fundadores y los dotadores nos dexaron». Archivo Histórico de Asturias (AHA). L. 11308, [prólogo]. Ha publicado el pasaje, junto con otras apreciaciones de interés, PAREDES NAVES, M. ${ }^{a}$ Concepción: «El archivo del monasterio de Santa María de Belmonte, especial referencia al Tumbo Nuevo», en Rodríguez Álvarez, Ramón (coord.): Pasión por Asturias. Estudios en homenaje a José Luis Pérez de Castro. Oviedo, Real Instituto de Estudios Asturianos, 2013, pp. 823-839. 
Asturias altomedieval. Fue fundada por los condes Pelayo Froilaz y María Ordoñez sobre la villa de Lapedo, que habían permutado con Vermudo III el año I032

En este espacio de la geografía astur se desenvolvía una sociedad marcadamente rural $^{5}$, que no parece haber permanecido ajena a la producción de escrituras de aplicación de derecho ${ }^{6}$. Poco sabemos de la génesis de los documentos de esta época, como será común hasta un tiempo posterior, y solo en algunos casos los diplomas recuerdan la condición clerical de sus autores materiales. De hecho, será el presbítero Martín quien antes de que finalice el siglo xı ponga por escrito la donación que hizo el conde don Fernando con su mujer a Juan Peláez, también presbítero, de las iglesias de San Andrés de Agüera y Villar de Zuepos7. Un poco más tarde será el presbítero Pedro quien haga lo propio con una donación de varias propiedades en Valdeparedes y Somiedo ${ }^{8}$.

En los años centrales del siglo xıl, Pedro Alfonso y María Froilaz reúnen las fracciones de aquella vieja propiedad, que había ido disgregándose entre varios herederos con el paso del tiempo, y, como harán otros conocidos magnates del entorno palatino de Alfonso vil ${ }^{9}$, fomentarán el asiento de una comunidad benedictina. Belmonte no se incorporaría al Císter hasta más tarde ${ }^{\mathrm{Io}}$, de la mano de Carracedo, abadía de la que fue filial ${ }^{\mathrm{II}}$.

Con la instalación de la comunidad de benedictinos a orillas del Pigüeña, a mediados del siglo xil, la actividad escrituraria de estos clérigos siguió siendo una realidad habitual. Para los vecinos alfoces rurales de Grado y Salcedo está bien documentado

4. Nuñez Contreras, Luis: «Colección diplomática de Vermudo III, rey de León», Historia. Instituciones. Documentos, 4 (1977), pp. 472-474 (documento 13) y 504.

5. Vide Fernández Mier, Margarita: «Economía y sociedad en Miranda y Somiéu en los siglos X-XIII», Asturiensia Medievalia, 8 (1995-96), pp. 111-132.

6. Calleja Puerta, Miguel: «A escribir a la villa. Clerecía urbana, escribanos de concejo y notarios públicos en la Asturias del siglo XIII», Historia. Instituciones. Documentos, 42 (2015), p. 60.

7. Floriano Cumbreño, Antonio C.: Colección diplomática del monasterio de Belmonte. Oviedo, IDEA, 1960, documento n. ${ }^{\circ} 4$.

8. Ibidem, documento n. ${ }^{\circ} 5$.

9. Al respecto puede verse, entre una bibliografía abundante, el estudio de conjunto de PÉREz-EMBID WAMBA, Javier: El Císter en Castilla y León. Monacato y dominios rurales (siglos XII-XV). Salamanca, Junta de Castilla y León, 1986, passim. Herráez Ortega, María Victoria: «Soberanos, señores y damas. Los promotores del Císter en el Reino de León», en Cavero Domínguez, Gregoria y Celis SánChez, Jesús (coords.): El Císter en el Reino de León. León, Instituto Leonés de Cultura, 2012, pp. 23 y ss. Para doña Sancha, vide MARTín LóPEz, M. a Encarnación: «Colección diplomática de la infanta doña Sancha (1118-1159). Estudio Crítico», en VV.AA.: León y su Historia. Miscelánea Histórica. VIII. León, Centro de Estudios e Investigación San Isidoro - Caja de España - Archivo Histórico Diocesano de León, 2003, pp. 159, 168-174. Sobre doña Sancha y sobre el propio emperador, CAVERo Domínguez, Gregoria: El esplendor del Císter en León. León, Fundación Vasco-Hullera, 2007, p. 25.

10. Sobre la fecha de incorporación de Belmonte al Císter: CoCHERIL, Maur: Etudes sur le monachisme en Espagne et au Portugal. Paris, Societé d'editions Les Belles Lettres, 1966, pp. 344 y 358; Fernández Conde, Francisco Javier: «Influencias foráneas y transformación de la sociedad asturiana a lo largo del siglo XII», Asturiensia Medievalia, 5 (1986), p. 119.

11. BALBOA DE PAZ, José Antonio: El monasterio de Carracedo. León, Instituto Leonés de Cultura, 2005 (2. ${ }^{a}$ edición), pp. 49-50. Un proceso similar al experimentado por la congregación encabezada por Carracedo debió de suceder, a mediados del siglo XII, con los monasterios que dependían de Savigny, que se incorporan de su mano al Císter. Uno de los últimos en referirse a la cuestión ALLEN, Richard: «À la recherche d'un atelier d'écriture de la Normandie cistercienne: le scriptorium de l'abbaye de Savigny (XII ${ }^{e}$-XIII' siècle)», en BAUDIN, Arnaud y MORELLE, Laurent (dirs.): Les pratiques de l'écrit dans les abbayes cisterciennes (XII'-milieu du XVI' siècle). Produire, échanger, contrôler, conserver. Paris, Somogy Éditions d'art, 2016, pp. 31-54. 
el desempeño de diáconos y presbíteros hasta bien entrado el siglo XIII ${ }^{\mathrm{I}}$. Por ello, los monjes de Belmonte, del mismo modo que muchos particulares y los incipientes concejos $^{13}$, acudirán a sus servicios, si bien no parece que haya sido lo habitual ${ }^{14}$.

Más frecuente será que el rogatario del documento no haga ostentación de su condición clerical; y mucho más habitual, no consignar ni el nombre al final de cada escrito. En realidad, la observación del modo en que suscriben los rogatarios permite apreciar los mismos rasgos reconocidos en otras latitudes ${ }^{15}$ : eclesiásticos, escribanos que indican su nombre sin aclarar su estatus, y por último un núcleo importante de documentos sin ninguna atribución de responsabilidad, cuya existencia se prolongará temporalmente más allá de la irrupción del notariado público en la región.

Sin embargo, en no pocas ocasiones, los propios monjes fueron los que pusieron por escrito sus documentos. Aún tras la primera aparición del notariado público de nombramiento real en el territorio continuaremos apreciando el recurso a amanuenses que no declaran estatus alguno, que no dejan constancia de su nombre, e incluso que se siguen reconociendo como miembros de la comunidad ${ }^{16}$.

Muchas veces, no obstante, como señalamos para el primer siglo largo de vida de la institución, varios documentos carecen de la suscripción de un amanuense que se identifique como tal. Es decir, atestiguamos la misma realidad que pudieron constatar, por ejemplo, Rosa María Blasco a partir de los documentos de Santo Toribio de Liébana, o María Terresa Carrasco Lazareno con los de Santo Domingo de Madrid, ya algo más tardíos ${ }^{17}$. Sin embargo, parece fuera de toda duda, a la luz de algunas de las escasas suscripciones de conventuales que nos han llegado ${ }^{18}$,

12. Fernández Ortiz, Guillermo: «La práctica notarial en el concejo de Grado (Asturias) durante el siglo XIII. De los escribanos rurales al notariado público», en PUEYO COLOMINA, Pilar (coord.): Lugares de escritura: la ciudad. Zaragoza, Institución Fernando el Católico, 2015, pp. 177-178.

13. LapeSA Melgar, Rafael: Asturiano y provenzal en el Fuero de Avilés. Salamanca, Universidad de Salamanca, 1948, pp. 4-5 (nota 9); Calleja PuerTA, Miguel: «Certezas y dudas sobre la tradición textual del fuero de Avilés de 1155», Revista de Filoloxía Asturiana, 9-10 (2009-10), pp. 219-220; IDEM: «El fuero de Avilés de 1155, original extracancilleresco de Alfonso VII», en Ruiz de La Peña Solar, Juan Ignacio, Sanz Fuentes, María Josefa, y Calleja Puerta, Miguel (coords.): Los fueros de Avilés y su época. Oviedo, RIDEA, 2012, pp. 441-442.

14. De hecho, únicamente tengo noticia de la escrituración del presbítero Juan González de una donación en favor de la abadía en 1245. Fernández Mier, Margarita: Documentos del Monesteriu de Balmonte (sieglu XIII). Oviedo, Academia de la Llingua Asturiana, 1995, p. 34, n. ${ }^{\circ}$ 25. [Fernández Mier: Belmonte I].

15. Para Portugal y Francia pueden verse, respectivamente: AzEVEDo SANTOS, María José: «Os «clérigos-notários» em Portugal (séculos XI-XII)», Estudos de diplomática portuguesa. Lisboa, Collibri-Universidade Coimbra, 2001, p. 77; y Tock, Benoît-Michel: Scribes, souscripteurs et témoins dans les actes privés en France (VII'-début XII siécle). Turnhout, Brepols, 2005, pp. 271-274. Para el caso castellano vide FERnÁndez FLórez, José Antonio: La elaboración de los documentos en los reinos hispánicos occidentales (ss. XI-XIII). Burgos, Institución Fernán González, 2002, passim. En Asturias, vide Calleja Puerta, Miguel: «A escribir a la villa. Clerecía urbana...», Historia. Instituciones. Documentos, 42 (2015), passim.

16. Fernández Mier, Margarita: Belmonte 1, 1995, n. ${ }^{\circ 5} 52$ y 69.

17. BLASCO, Rosa María: Una aproximación a la institución notarial en Cantabria. Santander, Universidad de Cantabria, 1990, p. 52 (nota 20); Carrasco Lazareno, María Teresa: La documentación de Santo Domingo el Real de Madrid (1286-1416). I. Estudio Documental, (Tesis doctoral inédita), Universidad Autónoma de Madrid, 1994, p. 700; IDEM: «Del scriptor al publicus notarius. Los escribanos de Madrid en el siglo xIII», Espacio, Tiempo y Forma. Serie III. Historia Medieval, 16 (2003), pp. 335 y ss.

18. Floriano Cumbreño, Antonio: Belmonte, 1960, n. ${ }^{\circ}$ 102; Fernández Mier, Margarita: Belmonte I, 1995, n. ${ }^{\circ 5}$ 25, $27,30$. 
de la data tópica («apud Lapideum») ${ }^{19}$ o de algunas fórmulas («en presencia del abad don $N$ y del convento del monasterio» ${ }^{20}$; o «esta carta mandé ý fazer a vos abbat et al conviento ${ }^{2 \mathrm{I}}$ ), que los monjes de Belmonte se procuraron sus propios documentos. Además, si a comienzos de la década de I230 documentamos a un escribano de nombre Juan Pístola ${ }^{22}$, en las de 1250 y I260 a tal nombre responde el prior del cenobio ${ }^{23}$. En una época en la que la comunidad procedía a la refacción de sus diplomas fundacionales y a la elaboración de un cartulario ${ }^{24}$, todo indica su importancia como lugar de escritura ${ }^{25}$. Entre estos monjes escritores habrá nombres que se repitan, mientras que otros sólo se documentan de manera esporádica. Se aprecia, aunque a menor escala, lo mismo que en la comunidad cisterciense de Santa María de Oscos, donde su abad Gómez protagoniza la escrituración de muchos documentos en el segundo cuarto del siglo Xill ${ }^{26}$, mientras que casos similares los documenta Mercedes Vázquez para la vecina Galicia ${ }^{27}$.

Con la implantación del notariado público en la región a mediados del siglo xıII, los monjes tendrán que recurrir progresivamente a sus servicios. Ahora bien, también es verdad que, en inicio, se mantendrán expectantes ante la aparición de las primeras escribanías concejiles y notarías públicas.

Sin embargo, al correr el tiempo, la necesidad les hará aceptar la novedad, de modo que, desde el último cuarto del siglo xılı, la práctica totalidad de escrituras del monasterio será validada por un notario público. El ejemplo que mejor muestra ambos procesos, así como la cronología de los mismos, es, sin duda, el traslado que en 1295 hace Pedro Cresfito, excusador en Cornellana en el barrio del obispo, por el notario del rey Arias Pérez, de una confirmación de donación en favor del monasterio que había tenido lugar en I267. En presencia de Teresa Gutiérrez, que había otorgado la referida donación, Pedro Cresfito hace traslado, palabra a palabra, para que sea «firme \& valiosso pora siempre \& porque aquel escripto non yera fecho por notario, nen seellado de seello antiguo $»^{28}$. Los tiempos

19. Fernández Mier, Margarita: Belmonte I, 1995, n. ${ }^{\circ 5} 5,7,11$.

20. Ibídem, n. ${ }^{\circ} 11,21,22,25,27,30,33,36 \ldots$, en todos ellos siendo abad, o don Nuño, o don Froila.

21. Ibídem, n. ${ }^{\circ} 23$.

22. Ibídem, n. ${ }^{\circ} 5$ y 9 .

23. Ibídem, n. ${ }^{\circ} 45$ y 69 .

24. SuÁrez GonZÁlez, Ana: «Partidos de cartularios. Una aproximación arqueológica a los ejemplares pregóticos de Oseira, Belmonte, Valparaíso y Valbuena», Cistercium, 248-249 (2006), pp. 406-407. También: FLORIANO CUMBREÑO, Antonio: Belmonte, 1960, pp. 18-19.

25. En el tránsito del siglo XII al XIII, fueron los monjes de Sandoval los que se ocuparon de los documentos de los que era destinataria la institución. SUÁREZ GONZÁLEZ, Ana: «Cultura escrita en Sandoval. Aproximación a la producción documental durante el abaciadgo de lohannes (1181-1201)», /l Congreso Internacional sobre el císter en Galicia y Portugal, II. Zamora, Montecasino, 1999, p. 921.

26. Álvarez Castrillón, José Antonio: Colección diplomática del monasterio de Santa María de Villanueva de Oscos (1139-1300). Oviedo, RIDEA, 2011, passim.

27. VÁzquez Bertomeu, Mercedes: «Notarios y documentos en Galicia (1100-1400): los monasterios cistercienses», II Congreso Internacional sobre el císter en Galicia y Portugal, II. Zamora, Montecasino, 1999, p. 998.

28. FERnÁNDEZ MIER, Margarita: Belmonte I, 1995, n. ${ }^{113 .}$ 
habían cambiado y lo que aún tenía valor a finales de la década de i26o carecía de ello a finales de la centuria.

Los monjes de Belmonte tendrán que acudir a una de las notarías públicas abiertas en los diferentes concejos o bien recurrir a los escribanos públicos nombrados por otros señores para actuar en sus señoríos. En el siglo xv solicitarán con mayor frecuencia los servicios de los «notarios públicos del rey en su corte, reinos y señoríos» y de los notarios apostólicos ${ }^{29}$, cuya onomástica remite inequívocamente a escribanos oriundos y asentados en el mismo territorio en el que se emplaza el monasterio (Fernando Moro de Grado; Álvaro Díaz de La Barca; Juan Peláez de Bello; Sancho Fernández de Bello...). En toda la Edad Media, el abad de Belmonte no podrá nombrar a un notario público en su jurisdicción, a diferencia de sus homólogos de Carracedo, que lo hace «en os soyus coutos de Dorna, Villaquinte, e de Padornelo e de Gestoso» ${ }^{30}$; de Oscos ${ }^{31}$; de Nogales ${ }^{32}$; y de los gallegos de Monfero, Melón o Meira33, que sí adquirieron dicha competencia.

Con la consolidación del notariado público de nombramiento real, los monjes de Belmonte, durante ioo largos años acudirán a las notarías públicas abiertas en las diferentes pueblas y concejos, preferentemente a las oficinas de Grado ${ }^{34}$, Somiedo y Miranda ${ }^{35}$ y, en menor medida, a las de Oviedo ${ }^{36}$, Salas o Pravia ${ }^{37}$. En unas ocasiones, serán los propios religiosos los que se desplacen a la villa a escribir y validar los negocios ${ }^{3}$, mientras que, en otras, los propios escribanos públicos serán

29. Señala cómo los monjes de Valdediós recurren también en el transcurso del siglo Xv a estos «notarios públicos del rey en su corte, reinos y señoríos», SANZ FUENTES, M. ${ }^{a}$ Josefa: «El monasterio de Valdediós, espacio para la escritura», Mosteiros Cistercienses. Actas do Congresso Internacional realizado em Alcobaça nos días 14 a 17 de junho de 2012, III. Alcobaça, 2013, p. 194.

30. Martínez Martínez, Martín: Cartulario de Santa María de Carracedo (992-1500). I. 992-1274. León, Instituto de Estudios Bercianos, p. 220, n. ${ }^{\circ} 927$.

31. Álvarez Castrillón, José Antonio: El monasterio de Santa María de Villanueva de Oscos. Historia y fuentes. Oviedo, Ayuntamiento de Villanueva de Oscos, 2010, p. 56; IDEM: El monasterio de Villanueva de Oscos. Guía didáctica. Oviedo, Ayuntamiento de Villanueva de Oscos, 2010, p. 62.

32. Cavero Domínguez, Gregoria: Colección documental del monasterio de Nogales (1149-1498). León, Centro de Estudios San Isidoro, 2001, pp. 356-359 (documentos 249 y 250).

33. VÁzquez Bertomeu, Mercedes: «Notarios y documentos en Galicia (1100-1400)...», I/ Congreso Internacional sobre el císter en Galicia y Portugal, II. Zamora, Montecasino, 1999, pp. 1003-1004.

34. Fernández Ortiz, Guillermo: «La práctica notarial en el concejo de Grado...», en Pueyo Colomina, Pilar (coord.): Lugares de escritura: la ciudad. Zaragoza, Institución Fernando el Católico, 2015, pp. 171-187.

35. Entre otros diplomas, Fernández Mier, Margarita: Belmonte I, 1995, n. ${ }^{\circ} 81,87,88$, 89 y 93. Fernández Mier, Margarita: Documentos del monasteriu de Balmonte (sieglos xIV y xV). Oviedo, Academia de la Llingua asturiana, 2001, n. ${ }^{\circ} 26,31,48,54-55,57-59,62,66-67,69-75,77-80,84,89-90,93,96-97,99-103,106-109,111,113,116-117,119-121,123-125$, 127-129, 132, 134, 139-140, 150, 152, 154, 161 y 162. AHN. Sección Clero. Regular. Cistercienses. Belmonte. Legajo 4937, [«Inventario de Hilario Prieto»], n. ${ }^{\circ} 14$ y 226. Archivo Real Chancillería de Valladolid. Pergaminos. Carpeta 76.7. En este listado se incluyen los casos en que aquellos notarios de nombramiento real, ejercicieron la publica fides bajo autoridad del conde don Alfonso y del príncipe de Asturias. Sobre estos útimos debe verse el trabajo de VIGIL MoNTES, Néstor: «Los notarios del Principado de Asturias: nombramiento y actuación», en PIÑOL ALABART, Daniel (coord.): La auctoritas del notario en la sociedad medieval: nominación y prácticas. Barcelona, 2015, pp. 163-176.

36. Fernández Mier, Margarita: Belmonte I, 1995, n. ${ }^{\circ} 50$, n. ${ }^{\circ} 100,116,117$ y 118.

37. Fernández Mier, Margarita: Belmonte I, 1995, n. ${ }^{\circ}$ 92, 106 y 107; Fernández Mier, Margarita: Belmonte II, 2001, n. ${ }^{\circ} 14$ y 43; Jovellanos, Gaspar Melchor de: Colección de Asturias mandada publicar por el Marqués de Aledo, tomo II (Edición de M. Ballesteros Gaibrois). Madrid, 1948, n. ${ }^{\circ} 236$. Para notario público de Pravia vide AHN. Sección Clero. Regular. Cistercienses. Belmonte. Carpeta 1570.10.

38. Calleja Puerta, Miguel: «A escribir a la villa. Clerecía urbana,...», Historia. Instituciones. Documentos, 42 (2015), 
los que se trasladen, ya al monasterio, ya al lugar en el que se emplazan los bienes que figuran en el negocio escriturado. Del mismo modo, el fondo documental de la abadía también permite apreciar la continua presencia, en los primeros años de la realidad notarial, de amanuenses, tenentes y excusadores, práctica que, no obstante, desaparecerá con el paso del tiempo; así como los hitos de ese cursus honorum notarial por el que no será extraño ver ejerciendo como escribano público a aquel que con anterioridad había sido excusador en la misma oficina ${ }^{39}$.

En los últimos años del siglo xiv la documentación belmontina permite apreciar bajo qué autoridad actuaban los notarios públicos en aquellos tumultuosos días. Vemos cómo un mismo notario reconoce, en función del momento, si la autoridad de la que emana su capacidad para autenticar un contrato es el rey o el conde don Alfonso ${ }^{40}$.

Los monjes de Belmonte no acudirán únicamente a los servicios de los notarios públicos de nombramiento real en las pueblas y concejos asturianos. También recurrirán a aquellos nombrados por los señores. Cuando los negocios que había que poner por escrito se referían a sus propiedades en los valles de Teverga, no fue extraño que solicitasen los servicios del escribano público de la abadía de San Pedro de Teverga, oficio que solía desempeñar uno de sus canónigos ${ }^{4}$. En fin, en el fondo documental de la abadía también consta el trabajo de los notarios públicos nombrados por el obispo de Oviedo para actuar en sus tierras de Las Regueras y Peñaflor ${ }^{42}$ o en Oviedo.

Paralelamente, y ante la existencia de partidas en favor del monasterio entre las mandas de los testamentos de la nobleza regional, los monjes frecuentarán algunas oficinas a las que rara vez solían acudir. Así, la revisión de la documentación nos permite ver cómo Pedro Suárez de Quiñones nombraba notarios en su señorío de Allande ${ }^{43}$; cómo el notario público en la puebla de Cangas lo era bajo la autoridad de don Domingo Pérez Ponce ${ }^{44}$; o cómo doña Isabel Ponce y el conde de Ribadeo tenían la capacidad de nombrar a los notarios de las pueblas

\footnotetext{
passim, y VázQuez Bertomeu, Mercedes: «Notarios y documentos en Galicia (1100-1400)...», en // Congreso Internacional sobre el císter en Galicia y Portugal, II. Zamora, Montecasino, 1999, p. 1002

39. Fernández Ortiz, Guillermo: «La práctica notarial en el concejo de Grado...», en Pueyo Colomina, Pilar (coord.): Lugares de escritura: la ciudad. Zaragoza, Institución Fernando el Católico, 2015, P. 183. Para la diócesis de Braga ha identificado idéntico proceso, en una cronología similar, CunHA ALEGRE, Maria Cristina Almeida e: «Tabeliães bracarenses no século XIII», IX Centenário da dedicação da sé de Braga. Congresso Internacional. Braga, 1990, p. 257; también Cunha Alegre, Maria Cristina Almeida e y Silva, Maria Joao: «Cooperazione e coesistenza tra professionist della scrittura: tabellioni pubblici e notai vescovili (Braga e Porto - sec. XIII-XIV)», en Musco, Alessandro y MusotTo, Giuliana (eds.): Coexistence and cooperation in the middle age. Palermo, Officina di Studi Medievali, 2014, pp. 448-449.

40. Por ejemplo, Fernández Mier, Margarita: Belmonte $11,2001, \mathrm{n} .^{\circ} 111$.

41. Ibidem, n. ${ }^{\circ} 49,65$ y 132.

42. Vide ANTUÑA CASTRO, Roberto: Notariado y documentación notarial en el área central del señorío de los obispos de Oviedo (1291-1389), (Tesis doctoral inédita), Universidad de Oviedo, 2014.

43. FERnÁNDEZ MIER, Margarita: Belmonte $11,2001, \mathrm{n} .{ }^{\circ} 114$.

44. Ibidem, n. ${ }^{\circ} 6$.
} 
de Tineo ${ }^{45}$ y Navia ${ }^{46}$ respectivamente. Como escribía Mercedes Vázquez, a mayor dispersión en los intereses y en la ubicación de bienes y propiedades, más variado es el elenco de escribanos públicos que podemos documentar a través de los fondos de un monasterio ${ }^{47}$.

Finalmente, observamos cómo, desde el segundo cuarto del siglo xv, los monjes asentados a orillas del Pigüeña prefieren acudir a los servicios de los notarios públicos del rey en su corte, reinos y señoríos que actúan en amplias demarcaciones rurales, próximas con toda probabilidad a su lugar de residencia; y, en menor medida, al concurso de notarios apostólicos, mal documentados en este archivo monástico, a pesar de que el monasterio seguirá sirviéndose de ellos en la primera mitad del siglo $\mathrm{XvI}^{48}$.

De todos modos, los monjes de Belmonte procuraron que algunas de las escrituras en que se fijaban sus negocios fueran validadas también con sellos, ya de los concejos, ya de otras instituciones religiosas ${ }^{49}$.

Además, fue habitual entre los siglos xill y xv que los monjes de Belmonte, del mismo modo que hacían los religiosos de las demás casas cistercienses de la Península Ibérica ${ }^{50}$, usasen el sello pendiente de cera, del abad primero y del monasterio también después, para validar especialmente contratos de carácter sinalagmático, como podía ser el caso de foros y arriendos ${ }^{51}$. Así, en un foro de I469 podemos leer «et por mayor firmeza seellámoslas con los seellos del dicho monesterio en caxa de çera pendiente con cuerdas segund costumbre del dicho monesterio» ${ }^{52}$, mientras que, en otro, otorgado un poco antes, la carta «que ha de ser pora el dicho Garçía Álvariz a de ser sygnada et sellada con los sellos de nos los dichos abad \& prior \& convento» ${ }^{53}$.

45. Ibidem, n. ${ }^{\circ} 94,98$ y 111 .

46. Ibidem, n. ${ }^{\circ} 110$.

47. VÁzquez Bertomeu, Mercedes: «Notarios y documentos en Galicia (1100-1400):...», Il Congreso Internacional sobre el císter en Galicia y Portugal, II. Zamora, Montecasino, 1998, p. 1000.

48. Luis González está documentado trabajando para el monasterio entre 1525 y 1542 y, en alguna ocasión, aparece mencionado como «escribano y notario apostólico». AHA. L. 11308, fols. 452 r. $^{\circ}-$ v. $^{\circ}$ (Foro de Fernando Gancedo en Villar de Vildas, 1525); 528r. ${ }^{\circ}$ (Apeo de Tineo, 1533); 517 r $^{\circ}$ y 521 . $^{\circ}$ (Apeo de Villazón y Camuño, 1536); y 476r. ${ }^{\circ}$ (Apeo de Villamor, 1542).

49. Por ejemplo, los otorgantes de una donación en favor de la abadía en 1290 pedirán al juez del concejo de Miranda que ponga el sello de este concejo; entre otros casos, vide Fernández MIer, Margarita: Belmonte I, 1995, n. ${ }^{\circ 5}$ 2, 83 y 109.

50. Sobre el uso de los sellos por parte de las abadías masculinas y femeninas del císter portugués, así como sus tipologías, vide, entre otras publicaciones del autor, Gomes, Saúl António: «Sigillis abbatis et conventus muniantur. A Sigilografía Cisterciense Medieval em Portugal», Signum, 9 (2007), pp. 21 y ss.

51. Arnaud Baudin ofrece el panorama general de la sigilografía cisterciense durante la Edad Media; BAUDIN, Arnaud: «Sceller à Clairvaux et dans sa filiation champenoise du XII au XVe siècle», en BAUDIN, Arnaud, DOHRMANN, Nicolas y VEYSSIÈre, Laurent (dirs.): Clairvaux l'aventure cistercienne. Paris, Somogy Éditions d'art, 2015, pp. 173-183.

52. Tomo la transcripción de Fernández Mier, Margarita: Belmonte $11,2001, n{ }^{\circ} 165$.

53. Ibidem, n. ${ }^{\circ} 163$. 


\section{I.2. LAS PRIMERAS PRÁCTICAS ARCHIVÍSTICAS}

Veremos ahora cómo una de las preocupaciones de los monjes del Belmonte anterior a la reforma fue la conservación de sus escrituras, y tan suyas eran las que se expedían en su favor como aquellas que se integraban en el fondo monástico con la adquisición de bienes. Lo señalaba no hace mucho Gregoria Cavero:

Ordenar, conservar y reproducir los diplomas aseguraba a las comunidades monásticas el control sobre su patrimonio territorial, cultural y espiritual. Así pues, nuestros monasterios dispusieron de importantes archivos donde se albergó la producción documental por ellos generada, la de una importante parte de sus linajes fundadores y la de cuantos bienes terminaron engrosando su patrimonio ${ }^{54}$

Así, en el archivo del monasterio de Belmonte nos encontramos, aún hoy, con un pequeño número de escrituras otorgadas entre particulares que, solo fruto de movimientos posteriores, pasó a formar parte del archivo monacal. Apenas superan la veintena, de modo que el número es ciertamente escaso en comparación con el porcentaje que tales escrituras supone en otros fondos ${ }^{55}$.

Poco más de media docena de estos documentos va fechada con anterioridad a los inicios de la vida regular en la abadía, y su incorporación al fondo de Belmonte tuvo lugar necesariamente años más tarde ${ }^{56}$. En algunos casos la fecha en que se agregó al archivo monástico se conoce con precisión, en otros algo puede apuntarse como posibilidad. Así, puede determinarse que no todas las escrituras temporalmente anteriores a la fundación del cenobio reformado formaron parte de la dotación fundacional. La compra que Mumadona González hizo a Oro Bellido de una heredad en Momalo (Grado), el año I092, no se debió de incorporar al archivo monástico hasta el año iı6o, cuando Elvira Martínez hizo entrega a los monjes de Belmonte de las heredades que había recibido de su marido Pedro González ${ }^{57}$. Solo un año antes había pasado al archivo monástico la donación del año Io98, que el conde don Fernando y su mujer, la condesa doña Enderquina,

54. Cavero Domínguez, Gregoria: El esplendor del Císter en León.... León, Fundación Hullera Vasco-leonesa, 2007, p. 249.

55. Por ejemplo, así lo señaló hace años para San Vicente de Oviedo Serrano, Luciano: Cartulario del monasterio de San Vicente de Oviedo. Madrid, Centro de Estudios Históricos, 1929, p. vII.

56. El proceso se conoce para otras latidudes y otros tiempos, Kosto, Adam: «Sicut mos esse solet: documentary practices in Christian Iberia, c. 700-1000», en Brown, Warren, CostambeYs, Marios, InNES, Matthew, y Kosto, Adam (eds.): Documentary Culture and the Laity. Cambridge, Cambridge University Press, 2013. En la catedral de Oviedo se incorporó tardíamente la donación de doña Fakilo, el original más antiguo, SANZ FUENTES, M. ${ }^{a}$ Josefa: «El documento de Fakilo (803): estudio y edición», Estudos em homenagem ao Professor Doutor José Marques, IV. Oporto, Universidad de Porto, 2006, pp. 31-40. También en la catedral de León sus diplomas más antiguos dependen más de su trayectoria en el siglo XII que de sus orígenes, CALLEJA PUERTA, Miguel: «Archivos dispersos, fuentes reencontradas. Notas metodológicas al estudio de las élites del reino de León en los siglos centrales de la Edad Media», Medievalismo, 12 (2002), p. 12. En Cluny ha insistido recientemente sobre el particular, INNES, Matthew: «On the material culture of legal documents: charters and their preservation in the Cluny archive, ninth to eleventh centuries», en BROWN, Warren, COSTAMBEYS, Marios, INNES, Matthew, y Kosto, Adam (eds.): Documentary Culture and the Laity. Cambridge, Cambridge University Press, 2013, pp. 290-301; el estudio es de BARRET, Sébastien: La mémoire et l'écrit: l'abbaye de Cluny et ses archives, $x^{e}$-XVIII'. Münster, LIT VERLAG, 2004, passim.

57. Floriano Cumbreño, Antonio: Belmonte, 1960. Documentos 3 y 45. 
habían hecho al presbítero Juan Peláez de sus bienes en los monasterios de Villar de Zuepos y Agüera. Fue entonces, en el año II59, cuando este último debió de entregarlos al monasterio ${ }^{58}$.

Interesa de todos modos este documento por una cuestión más, y es que en él no se hace mención alguna a los bienes de Villar de Zuepos. Además, resulta significativa la omisión u olvido, pues del mismo conservamos dos copias, una interpolada, a juicio de Antonio Floriano, que incorpora el deslinde de la propiedad de Agüera, y ambas con un post scriptum según el cual Martín Albo, que debía disfrutar del usufructo vitalicio de estos bienes antes de que pasaran al patrimonio monástico, se comprometía al pago de un canon anual de escanda y vino ${ }^{59}$. El caso es que este mismo Martín Albo vuelve a figurar un poco más tarde comprando a Pedro Díaz y a sus sobrinos una heredad en la villa de Villar de Zuepos, por el precio de un buey y una yegua. No hay noticia de la integración en el fondo monástico de esta última, pero no sería extravagante pensar en que esta pasase al monasterio a la muerte del propio Martín Albo, o en compensación por aquellos pagos no satisfechos que se incorporaron solo tardíamente al documento del presbítero Juan Peláez y que, a la larga, acabarían posibilitando que los bienes de Villar de Zuepos pasasen al abadengo de Belmonte.

El mayor lote se incorporará, sin embargo, con la dotación fundacional de Pedro Alfonso o, como muy tarde, en alguna de sus donaciones posteriores. Así, en primer lugar, están las cartas que acreditan el modo en que este adquirió a sus hermanos Aldonza y Gonzalo y a su primo Vela Gutiérrez ${ }^{60}$ sus partes en el viejo monasterio en régimen de herederos ${ }^{61}$.

Fruto de sucesivas donaciones y gracias concedidas al monasterio por Pedro Alfonso y su mujer María Froilaz se incorporarán al archivo de Belmonte la donación que Sancho Sánchez hizo a Elvira Velázquez de la mitad de la villa de Murias y de la de Camino, en el territorio de Somiedo, que había pasado a poder del conde antes de iı64, momento en que las entregó a los monjes del Pigüeña ${ }^{62}$. Poco antes el matrimonio condal había comprado a Sancha Ordóñez un buen número de bienes en los alfoces de Teverga, Miranda, Candamo, Grado, Somiedo y Pravia, y permutado con María Fafilaz y su hijo Gutierre Velázquez unos bienes en plena cordillera Cantábrica, y aún al sur de la misma, por otros emplazados en los alfoces de Salcedo, Las Regueras, Tineo y Prámaro $^{63}$ que muy posiblemente pasaron a engrosar el patrimonio monástico en la cuantiosa donación de abril de II57. Con

58. Ibidem. Documentos 4,42 y 43 .

59. Ibidem. Documentos 42 y 43.

6o. El parentesco en Calleja Puerta, Miguel: El conde Suero Vermúdez, su parentela y su entorno social. La aristocracia asturleonesa en los siglos XI y XII. Oviedo, KRK, 2001, passim.

61. Floriano Cumbreño, Antonio: Belmonte, 1960. Documentos 7 y 8; Hevia Ballina, Agustín: «Un inventario de documentos que formaron parte del archivo del monasterio cisterciense de Santa María de Lapedo en Belmonte», Studium Ovetense, 20 (1997). Documento 204.

62. Floriano Cumbreño, Antonio: Belmonte, 1960. Documentos 32 y 33.

63. Ibidem. Documento 34 . 
motivo de esta, el conde habría hecho entrega de las cartas que acreditaban parte de esos bienes, al menos de los adquiridos en los años precedentes.

Estos diplomas, en todo caso, no son más que una parte del rico archivo que debió poseer el conde ${ }^{64}$. A medida que este, junto con sus mujeres (primero María Froilaz y luego Sancha Fernández), fue entregando bienes a diferentes instituciones religiosas, otras cartas abandonaron el archivo condal con destino al depósito documental de estos centros; al mismo tiempo también estuvo en relación con miembros que no pertenecían al estamento clerical ${ }^{65}$. Entre los centros religiosos, sabemos que el conde benefició a la abadía de San Pedro de Teverga ${ }^{66}$, al monasterio cisterciense de Vega ${ }^{67}$, al de Lorenzana ${ }^{68}$, al de Nogales ${ }^{69}$, a la orden de San Juan $^{70}$, muy posiblemente a San Isidoro de León ${ }^{71} y$, en fin, también al de Otero de las Dueñas, en cuyo archivo se conservan más de una decena de pergaminos en los que son beneficiarios o partícipes Pedro Alfonso y su primera mujer, María Froilaz $^{72}$. Más tarde, su hija Elvira dará a la orden de Santiago los bienes que de su padre había heredado en Toledo ${ }^{73}$.

Otros documentos se fueron integrando en el archivo monástico con motivo de testamentos ${ }^{74}$, de compra-ventas por parte del monasterio ${ }^{75}$, como fruto de una avenencia ${ }^{76}$, etc. En la inmensa mayoría desconocemos el modo y el momento en que pasaron a formar parte del patrimonio documental de la comunidad. Bien ha podido perderse el documento que recogía la transacción al monasterio, o bien

64. Esto parece haber sido lo habitual desde la Alta Edad Media, dada la homogeneidad que apreciamos en el patrimonio entregado a estas, BULLIMORE, Katherine: «Folcwin of Rankweil: the world of a Carolingian local official», Early Medieval Europe, 13 (2005), p. 57.

65. Fernández Martín, José Luis: Orígenes de la Orden militar de Santiago (1170-1195). Barcelona, CSIC, 1974, pp. 174-175. Documento 5.

66. García Larragueta, Santos Agustín: Colección de documentos de la catedral de Oviedo. Oviedo, IDEA, 1962. Documento 159 .

67. Serrano, Luciano: Cartulario del monasterio de Vega con documentos de San Pelayo y Vega de Oviedo. Madrid Centro de Estudios Históricos, 1927, pp. 75-76. Documento 53.

68. Rodríguez GonzÁlez, Ángel y Rey Caiña, José Ángel: «El Tumbo del Monasterio de Villanueva de Lorenzana», Estudios mindonienses, 8 (1992), p. 76. Documento 37.

69. VAlCARCE, María Amparo: El dominio de la Real colegiata de San Isidoro de León hasta 1189. León, Institución fray Bernardino de Sahagún, 1985, pp. 164-165. Documento 89.

70. Ayala Martínez, Carlos: Libro de privilegios de la orden de San Juan de Jerusalén en Castilla y León (siglos XIIXv). Madrid, Instituto complutense de la orden de Malta, 2005, pp. 280-281. Documento 111. Tras él, su segunda esposa también favorecerá a la orden con los bienes recibidos de este en arras. Ibidem, documento 131.

71. Hay una carta procedente del archivo condal, de la que desconocemos su modo de integración en el fondo. ValCARCE, María Amparo: El dominio de la Real colegiata.... León, Institución fray Bernardino de Sahagún, 1985. Documento 72 .

72. Fernández Flórez, José Antonio y Herrero de la Fuente, Marta: Colección documental del monasterio de Santa María de Otero de las Dueñas. II (1109-1300). Índices. León, Centro de Estudios e Investigación San Isidoro - Caja España de Inversiones - Archivo Histórico Diocesano, 2005. Documentos 335, 336, 342, 343, 347, 348, 349, 352, 354 y 356. El último en referirse ampliamente a este lote, CALLEJA PUERTA, Miguel: «Señores sin cancillería. Génesis y validación de los documentos de la aristocracia castellano-leonesa (1100-1250 ca.)», en SUÁREZ GonzÁlezZ, Ana (ed.): Escritura y Sociedad: la nobleza. Santiago de Compostela, Universidad de Santiago - Xunta de Galicia, 2017, p. 24.

73. Fernández Martín, José Luis: Orígenes de la Orden militar.... Barcelona, CSIC, 1974, p. 247. Documento 72.

74. Fernández Mier, Margarita: Belmonte II, 2001. Documentos 107 y 143.

75. Ibidem. Documento 141.

76. Fernández Mier, Margarita: Belmonte I, 1995. Documento 106. 
pasó a formar parte del archivo de la institución al ingresar como religioso en la abadía el propio beneficiario del acto anterior o uno de sus descendientes. A raíz de esto último puede plantearse el itinerario recorrido por la carta que el conde fundador Pedro Alfonso entregó a su hermano, Rodrigo, tras haberle vendido una propiedad en Villamarín. De la vida de Rodrigo Alfonso nada sabemos, más allá de que seguía vivo a principios de la década de $1180^{77}$; sin embargo, no deja de resultar llamativo el hecho de que en I2I7 sea un tal Alfonso Rodríguez quien entregue al abad del monasterio de Belmonte, Pedro Rodríguez, su hermano, la propiedad que tenía en Villamarín y que, nuevas propiedades en este lugar las entregue al monasterio en I23I Mayor Rodríguez, insistiendo en que las poseía tanto de ganancia como heredadas de sus antepasados. Si esta hipótesis fuese correcta, el monasterio continuaría en los primeros años del siglo xıı bajo el dominio de la parentela de los fundadores, o muy próximo a la órbita del núcleo familiar que lo dotó a mediados del siglo anterior.

\section{I.2.1. Conservación, descripción, organización y refacciones}

Para proteger el tenor documental, la primera práctica fue plegar los documentos, doblándolos sobre sí mismos. El modo de proceder es el mismo que se documenta en numerosos lugares desde la Alta Edad Media ${ }^{78}$.

A partir de estas dobleces podemos distinguir diferentes campañas o momentos de depósito de las escrituras en el fondo. Así, en una primera época, con anterioridad al año I200, los documentos estaban mucho más plegados sobre sí de lo que lo estarán desde la segunda mitad de siglo xılı, y siempre con la cara escrita hacia adentro ${ }^{79}$.

Además de esta práctica, los sucesivos monjes que tuvieron a su cargo el archivo procedieron a dotar de notas dorsales a las escrituras ${ }^{80}$. Nunca se llegaron a fijar cotas de archivo, es decir, signaturas que remitieran a una organización interna del fondo como sí se ha apreciado en otros lugares ${ }^{81}$. Identificamos para

77. Calleja Puerta, Miguel: El conde Suero Vermúdez..., Oviedo, KRK, 2001, p. 116.

78. Con detalle, para el caso de Santa Cruz de Coimbra, Gomes, Saul António: In Limine conscriptionis. Documentos, chancelaria e cultura no mosteiro de Santa Cruz de Coimbra (séculos XII a XIV). Viseu, CHSC, 2007, pp. 264 y ss.

79. Mendo Carmona, Concepción: «El pensamiento archivístico medieval. Una página de la historia de la cultura a través del fondo documental de la catedral de León», en Soto RÁBAnos, José María (coord.): Pensamiento medieval hispano. Homenaje a Horacio Santiago-Otero, I. Madrid, CSIC, 1998, p. 604.

80. Sobre la labor de los archiveros medievales, detectable a partir de estas notas, vide: GomES, Saul António: In Limine conscriptionis... Viseu, CHSC, 2007, p. 247 (nota 12). Sobre las precauciones a la hora de su interpretación se manifiesta, entre otros, CRUz HERRANZ, Luis Miguel: «El archivo monástico. Entre la gestión de su administración y la gestión de su memoria histórica», en BALDAQUí ESCANDELL, Ramón (ed.): Lugares de escritura: el monasterio. Alicante, Universidad de Alicante, 2016, p. 184

81. ERHART, Peter: «Carta ista amalfitana est et nescitur legere. The charters of Cava dei Tirreni and their evidence for early medieval archival practice», Gazette du livre medieval, 50 (2007), pp. 27-39; para Cluny ha estudiado el tratamiento archivístico BARRET, Sébastien: La mémoire et l'écrit:... Münster, LIT VERLAG, 2004, pp. 9, 25 y 124. 
los tiempos medios únicamente una pequeña descripción del contenido del diploma, reducida en la generalidad de casos a una referencia al lugar al que se refiere su contenido, a su otorgante, y a lo sumo una clasificación (diplomática/ jurídica) del tipo documental. Transcurrido el tiempo, en los años finales de la Edad Media y especialmente en la primera mitad del siglo xvı, nos encontraremos con descripciones más precisas que incorporan el nombre de los otorgantes, así como alguna que otra apreciación de desigual valor.

En muchas ocasiones las posteriores labores de reorganización, de descripción documental y de fijación de nuevas signaturas impiden la lectura de cotas y anotaciones anteriores.

Las notas más antiguas pueden fecharse en la segunda mitad del siglo xII, y serían prácticamente coetáneas a la escrituración de los propios documentos. Encontramos estas notas en los dorsos de unos de los pocos documentos originales que conservamos del siglo xil.

Ya Antonio Floriano observó cómo «al llegar el siglo xıII algo debió de ocurrir en relación a la documentación conservada, pues casi la mitad de los documentos originales desaparecieron y hubieron de ser substituidos por copias (...)» ${ }^{82}$. Así, muchos de los documentos referidos al primer medio siglo largo de andanza de la institución son sustituídos por unas refacciones, de mayor o menor fiabilidad histórica, que garantizaran mejor los intereses de la comunidad asentada a orillas del Pigüeña. Este proceso, según la estimación cronológica que Antonio Floriano atribuye a las copias, habría tenido continuidad, o más bien se habría prolongado durante muy buena parte del siglo xıI, y permite acercarse a los primeros procesos de producción, conservación y transmisión de documentos en el seno de la entidad monástica. Julio Escalona relaciona la elaboración de estas copias simples (en este caso más o menos adulteradas) con labores de gestión documental, «aunque apenas podamos entrever cuáles fueron sus motivos y objetivos concretos» ${ }^{83}$.

La realización de diversas copias simples de un mismo documento es, en todo caso, conocida desde la Alta Edad Media ${ }^{84}$. Independientemente de la voluntad de falsificación documental, lo cierto es que, para la conservación de los diplomas que estimaban de más valor, los monjes procuraron disponer siempre de varias copias del ejemplar, primero simples, y desde la implantación del notariado en la región autorizadas con su signo. Esto se aprecia perfectamente con la donación que Fernando Il hizo de su heredad de Páramo con la iglesia de San Justo, de la

\footnotetext{
82. Floriano Cumbreño, Antonio: Belmonte, 1960, p. 16.

83. Lo señala, es cierto que para un período algo anterior (ss. X-XI), EsCALONA MongE, Julio: «Antes de los cartularios: gestión de archivos y transmisión de los documentos de la Castilla condal (siglo IX-1038)», en SIRANTOINE, Hélène, y Escalona Monge, Julio (coords.): Chartes et cartulaires comme instruments de pouvoir: Espagne et Occident chrétien (VIII'-XII' siècles). Madrid, CSIC - Universidad de Toulouse, 2013, p. 153.

84. ZIELINSKI, Herbert: «The trasmission of Lombard documents (to 774)», en Kosto, Adam y WINROTH, Anders (eds.): Charters, cartularies and archives. Toronto, Pontifical Institute of Mediaeval Studies, 2002, p. 38. En la catedral de Oporto el fenómeno está documentado a lo largo de todo el medievo: SILVA, Maria Joao: A escrita na catedral. A Chancelaria episcopal do Porto na Idade Média. Lisboa, CITCEM, 2013, p. 227.
} 
que disponemos del original ${ }^{85}$, de una copia coetánea ${ }^{86}$, de otra de la primera mitad del siglo XIII ${ }^{87}$ y de dos traslados notariales de comienzos del siglo XIV ${ }^{88}$. De su importancia da cuenta la moderna nota dorsal que hallamos en otro pergamino del archivo monástico: «pusosele esta funda porque está muy maltratado [el original de Fernando II]» ${ }^{89}$.

De todos modos, en el primer tercio del siglo xill, los monjes no se conformaron con la realización de copias simples de los documentos que paraban en su archivo, al menos de los más importantes. Por esto, sobre estas copias se elaboró un cartulario. De él únicamente conocemos un bifolio inconcluso que contiene seis diplomas, dos de ellos íntegros, pues los folios no son consecutivos. El copista reservó espacios en blanco para insertar iniciales o un incipit que sirviera como elemento de articulación y que estaría previsto realizar en tinta roja. Se sabe cuál es el texto ausente «gracias a las notas de taller que dispuso perpendicularmente en espacios marginales» ${ }^{90}$. Ana Suárez resalta la calidad del material y del proyecto, pese a su carácter de inacabado, mientras Antonio Floriano no llega a determinar si este fue un bifolio desechado o sencillamente la elaboración del cartulario no fue más que un intento frustrado ${ }^{91}$.

En todo caso, resulta relevante que, de estos seis diplomas copiados, cuatro sean privilegios reales de Alfonso VII y Fernando II, y que con ellos también encontrara acomodo una donación otorgada por el conde fundador. Así, figuran la donación de Pedro Alfonso del año II5I, la concesión de coto de marzo de ese mismo año por parte del Emperador, o la entrega del realengo de Novellana que hizo en II63 el rey Fernando $11^{92}$, con la que el monasterio conseguía salida al mar.

La elaboración de este cartulario permite contemplar un archivo ya maduro, sometido a una nueva organización, a un nuevo proceso de reactualización de la memoria escrita que atiende a los principios de gestión, protección y conmemoración del poder, identificados en su día por Patrick Geary como pilares angulares a los que respondía su elaboración ${ }^{93}$. En él se copiaron aquellos documentos que interesaban, al ser elementos justificativos del poder de la entidad monástica. El cartulario de Belmonte refleja ese complejo proceso de acumulación, selección y

85. AHN. Sección Clero. Regular. Cistercienses. Belmonte. Carpeta 1569.20.

86. AHN. Sección Clero. Regular. Cistercienses. Belmonte. Carpeta 1569.21.

87. AHN. Sección Clero. Regular. Cistercienses. Belmonte. Carpeta 1569.22.

88. AHN. Sección Clero. Regular. Cistercienses. Belmonte. Carpeta 1569.23 y 24.

89. AHN. Sección Clero. Regular. Cistercienses. Belmonte. Carpeta 1583.06.

90. SuÁrez González, Ana: «Partidos de cartularios...», Cistercium, 248-249 (2007), pp. 406-408.

91. Floriano Cumbreño, Antonio: Belmonte, 1960, p. 19.

92. Ibidem. Documentos 20, 21 y $63 \mathrm{~F}$.

93. Sanz Fuentes, M. ${ }^{a}$ Josefa: El Tumbo Negro de la Catedral de Astorga. Aproximación a su historia. Astorga, Centro de Estudios Astorganos Marcelo Macías, 2010, pp. 14-15; en esta misma idea Calleja PuerTA, Miguel: «Archivos dispersos, fuentes reencontradas...», Medievalismo, 12 (2002), p. 20; IDEM: «Cartularios y construcción de la memoria monástica en los reinos de León y Castilla durante el siglo XII», en LAMAZOU-DUPLAN, Véronique y RAmírez VAQUERO, Eloísa (dirs.): Los cartularios medievales. Escribir y conservar la memoria del poder, el poder de la memoria. Pau, Universidad de Pau, 2013, pp. 190-192. 
filtrado en el que ha insistido recientemente Julio Escalona ${ }^{94}$, y no sería extraño vincular su elaboración a las averiguaciones de Alfonso IX en la región ${ }^{95}$, momento, por ejemplo, en que los monjes del vecino monasterio benedictino de Corias elaboraron su Registrum, que fue llevado ante el propio rey ${ }^{96}$. Sin embargo, en este proceso de cartularización -en términos de Pierre Chastang ${ }^{97}-$, la «reescritura» ${ }^{8}$ de los documentos parece haberse limitado a una transcripción muy ajustada sobre las copias de unos originales que, en caso de no haber desaparecido ya, no fueron tenidos en consideración.

Del cartulario de Belmonte no sabemos mucho más. Un buen número de pergaminos contiene al dorso la anotación «escrita», todos ellos referidos a bienes situados en los concejos de Grado y Teverga. Esta anotación invitaba a pensar que podía indicarnos aquellas escrituras seleccionadas para ser trasladadas al cartulario, siguiendo en ello el habitual orden topográfico ${ }^{99}$; sin embargo, no hemos logrado identificar rastro de una anotación semejante en alguno de los documentos que sí fueron copiados en el bifolio como sucede con la concesión de coto por Alfonso VII, la donación de Novellana de Fernando Il, o el testamento del conde Pedro Alfonso del año $\mathrm{II}_{5} \mathrm{I}^{\mathrm{IOo}}$.

Por lo demás, cabe añadir únicamente que, hasta la reorganización de fines del siglo xvi, no hubo una sola campaña en toda la Edad Media en que se procediera a rotular sistemáticamente el dorso de los diplomas. Hay anotaciones en carolina que pueden datarse hacia $\mathrm{I}_{20 \mathrm{O}^{\mathrm{IOI}}}$, mientras que un buen número de ellas estarán escritas en una gótica cursiva fracturada usual, consolidada en la región

94. Escalona Monge, Julio: «Antes de los cartularios:...», en Sirantoine, Hélène y Escalona Monge, Julio (coords.): Chartes et cartulaires comme instruments de pouvoir: Espagne et Occident chrétien (VIII'-XII siècles). Madrid, CSIC-Universidad de Toulouse, 2013, p. 147.

95. La práctica totalidad de este material se ha perdido. La bibliografía regional apenas se ha acercado a esta cuestión, Calleja Puerta, Miguel: «La Asturias medieval», en Fernández Pérez, Adolfo y Friera SuÁrez, Florencio (coords.): Historia de Asturias. Oviedo, KRK, 2005, p. 222. También se refiere a ello Manuel Lucas en su estudio sobre la cancillería del monarca. Vide LuCAS ÁlvareZ, Manuel: «La Cancillería de Alfonso IX (1188-1230)», El reino de León en la Alta Edad Media v. Las Cancillerías Reales (1109-1230). León, Centro de Estudios San Isidoro - Archivo Histórico Diocesano de León - Caja España, 1993, pp. 569-570.

96. SÁez SÁNCHEZ, Carlos: «Códices diplomáticos y conservación documental», Acta historica et archaeologica mediaevalia, 25 (2003-04), pp. 838-839.

97. CHASTANG, Pierre: «Cartulaires, cartularisation et scripturalité médiévale: la structuration d'un nouveau champ de recherche», Cahiers de Civilisation Médiévale, 49 (2006), pp. 21-31; también, aunque referido a una etapa algo anterior, Calleja Puerta, Miguel: "Cartularios y construcción de la memoria monástica...», en Lamazou-Duplan, Véronique y Ramírez Vaquero, Eloísa (dir.): Los cartularios medievales. Escribir y conservar la memoria del poder, el poder de la memoria. Pau, Universidad de Pau, 2013, pp. 194-195.

98. Emplea la expresión en su triple significación: SANz Fuentes, M. ${ }^{a}$ Josefa: La reescritura del pasado. El Liber testamentorum de la catedral de Oviedo. Oviedo, Universidad de Oviedo, 2014, p. 17.

99. Para el Cartulario Blanco de Saint Dennis así se ha visto, por ejemplo: primero los documentos fundamentales para la abadía y luego el resto distribuído según un criterio topográfico, GUYOTJEANNIN, Olivier: «La science des archives a Saint-Denis (fin du XIII $I^{e}$-debut du XVI ${ }^{e}$ siécle)», en Autrand, Françoise, GauVArd, Claude, y Moeglin, Jean-Marie (coord.): Saint-Denis et la Royauté. Études offertes à Bernard Guenée. Paris, Publications de la Sorbonne, 1999, p. 342; criterio administrativo (en granjas y cilleros) se llevó en el que, hacia 1230, se confeccionó en Claraval, VEYSSIÈRE, Laurent: «Les archives de Clairvaux: outil de gestion du temporel», en BAUDIN, Arnaud, DOHRMANN, Nicolas, y VEYSSIĖRE, Laurent (dirs.): Clairvaux l'aventure cistercienne. Paris, Somogy Éditions d'art, 2015, p. 162.

100. AHN. Sección Clero. Regular. Cistercienses. Belmonte. Carpetas 1568.01; 1568.02; 1568.03; 1568.04 y 1568.20.

101. AHN. Sección Clero. Regular. Cistercienses. Belmonte. Carpeta 1570.16 (1181). 
en la segunda mitad del siglo xıIl, y que suelen ceñirse a la mención del lugar al que se refiere la escritura: «De Cañedo» ${ }^{102}$, «de Montobo» ${ }^{\mathrm{ro3}}$, etc. No obstante, ya a mediados de siglo aparecen descripciones mucho más prolijas, coetáneas muy posiblemente a la propia escritura, a cargo de manos que aún no han olvidado todos los rasgos de la carolina.

Un poco posterior parece la mano que escribe la nota de «Concanbia de Belandres et de Ballo por Monteziello» ${ }^{\text {I04 }}$ sobre una escritura del año ir6o y que emplea para ello una gótica cursiva fracturada corriente (s sigma, ojo superior en la $d$ ). Finalmente, hacia finales de siglo xv o principios del siglo xvı, las descripciones de estas notas dorsales son mucho más minuciosas y ya suelen incluir, siguiendo la tendencia que apreciamos en el ejemplo anterior, la referencia al tipo documental ante el que nos hallamos, la naturaleza del bien que se contiene en la escritura, y el lugar en el que se emplaza. Así, por ejemplo: «donaçión de la parte que tiene el monasterio en Santa María de Rastiello» ${ }^{105}$ o «donaçión de Muros y de [...] $»^{106}$.

Ya para entonces el archivo era una realidad ampliamente consolidada. Ya nos referimos al hábito de los monjes de plegar las escrituras sobre sí, o a la costumbre de realizar varias copias de una misma escritura, aunque las primeras fueran refacciones más o menos fraudulentas. Tras la implantación del notariado, acudirán a las oficinas notariales no ya para la expedición de los nuevos contratos, sino también para solicitar el traslado de cartas que carecían de la oportuna garantía jurídica. Al notariado público recurrirán también para obtener traslado de aquellas cartas que temían perder por causa de fuego, de agua o de hurto ${ }^{107}$, especialmente de documentos otorgados por la corona sobre papel.

En fin, ya desde I26I tenemos las primeras referencias al archivo, que aparece designado bajo la voz «escritorio» ${ }^{108}$. Así, de una donación que hace Juan Tomás con sus hijos se dice «\& en vostro scritorio la metemos» ${ }^{109}$.

En el siglo xv seguimos encontrando referencias a este espacio que ahora aparece designado bajo la voz «cartolario», de modo que la comunidad sigue teniendo destinado un espacio para la guarda de aquella documentación que veíamos se iba describiendo en el dorso de las propias escrituras. Así, en abril de I477 los

102. AHN. Sección Clero. Regular. Cistercienses. Belmonte. Carpeta 1574.20 (1259).

103. AHN. Sección Clero. Regular. Cistercienses. Belmonte. Carpeta 1575.16.

104. AHN. Sección Clero. Regular. Cistercienses. Belmonte. Carpeta 1569.07 (1160).

105. AHN. Sección Clero. Regular. Cistercienses. Belmonte. Carpeta 1567.20.

106. AHN. Sección Clero. Regular. Cistercienses. Belmonte. Carpeta 1568.19.

107. Fernández Mier, Margarita: Belmonte I, 1995, p. 152. Documento 118; IDEM: Belmonte II, 2001, p. 297. Documento 156.

108. Frente al habitual empleo para estos años del término «tesoro» u otro similares (también cartorio, u otras voces semejantes) que se documenta, por ejemplo, en la catedral de Oviedo aún hacia 1300, CALLEJA PUERTA, Miguel: «La Catedral de Oviedo como centro de conservación de documentos en la Alta Edad Media», Estudos em homenagem ao Professor Doutor José Marques, IV. Oporto, Universidad de Porto, 2006, p. 191; en el siglo XIV aparece ya designado como archivio publico, SANZ FUENTES, M. a Josefa: «Estudio paleográfico», en VV.AA.: Liber Testamentorum Ecclesiae Ovetensis. Barcelona, Moleiro, 1995, pp. 97-98. Vide también su uso en el siglo xIII en Santa Cruz de Coimbra, Gomes, Saul António, In Limine conscriptionis... Viseu, CHSC, 2007, p. 262.

109. FERnÁNDEZ Mier, Margarita: Belmonte I, 1995. Documento 64. 
monjes de Belmonte solicitan a Arias González de Menes, notario público del rey en su corte, reino y señoríos, que «feziese dos cartas», una «que non tenga sello ninguno (...) para guarda en el cartolario del dicho (...) monesterio» ${ }^{\mathrm{HI}}$. Aunque, como es sabido, la voz 'cartulario' tiene carácter polisémico a lo largo de la Edad Media $^{\text {III }}$, no hay duda de que en esta ocasión nos permite reconocer un espacio destinado a la guarda y custodia del fondo documental, posiblemente similar al armarium (biblioteca) identificado en los también monasterios cistercienses de Valdediós ${ }^{\mathrm{II} 2}$, Huerta ${ }^{\mathrm{II} 3}$ o Piedra ${ }^{\mathrm{II} 4}$, entre otros, documentados ya en el xill.

En la Baja Edad Media, en esos años de relajación religiosa y abades perpetuos, existía un espacio para la guarda de la documentación y estaba extendida la costumbre de anotar al dorso de cada diploma una sinopsis de su contenido de cara a facilitar su localización. Sin embargo, no parece que llegase a surgir entre los religiosos del Pigüeña la necesidad de dotar de un orden lógico la distribución de las escrituras en ese archivo.

En los primeros años del XVI ${ }^{\mathrm{II} 5}$ las escrituras estaban dispuestas en envoltorios. Así, en el dorso de una carta de donación de Montobo leemos «Memoria de las escripturas que están en este enboltorio ${ }^{116}$. Entre ellas: una donación de una hacienda en Montobo, de media iglesia en Llamoso, de la Fuente en Casazorrina, varias escrituras de Montobo y Llamoso, un foro en Faidiello, apeo de unos bienes en Tineo, foro de las viñas de Castiello ${ }^{117}$ y foro de Agüera, entre otras. La impresión que trasluce esta enumeración es la de un archivo cuyo orden no obedece a alguna de las lógicas habituales en la época: No están ordenadas topográficamente y tampoco lo están tipológicamente. La sensación que dejan los datos reunidos en la tabla adjunta es que en modo alguno existe un orden cronológico.

De todos modos, en lo que se refiere a la descripción se consignan datos habituales: tipología jurídica, emplazamiento del bien y naturaleza de ese bien ${ }^{\mathrm{II} 8}$.

110. Fernández Mier, Margarita: Belmonte II, 2001, pp. 329-331. Documento 167

111. SÁez SánCHez, Carlos: «Origen y función de los cartularios hispanos», Gazette du livre médiéval, 46 (2005), p. 38; Mendo Carmona, Concepción: «Los tumbos medievales desde la perspectiva archivística», en VV.AA.: Jornadas científicas: documentación jurídico-administrativa, económico financiera y judicial en el reino castellano-leonés (s. $x$-XIII). Madrid, Universidad Complutense, 2002, p. 166.

112. Torné Cubetls, Josep: «El armarium de Valdediós», Actas del II Congreso de Bibliografía Asturiana, III. Oviedo, Consejería de Educación y Cultura del Principado de Asturias, 1999, p. 1083.

113. García Luján, José Antonio: Cartulario del monasterio de Santa María de Huerta. Soria, Monasterio de Huerta, 1981, p. XVIII.

114. González Hymla, Herbert: El monasterio de Piedra. Fuentes y documentos. Madrid, Real Academia de la Historia - Institución Fernando el Católico, 2014, p. 25.

115. Una carta de 1504 lleva escrita nota al dorso por la misma mano que hace la relación de los inventarios. AHN. Sección Clero. Regular. Cistercienses. Belmonte. Carpeta 1584.14. «Donation de la >juguería< de la Collada».

116. Conservamos la relación de dos envoltorios: AHN. Sección Clero. Regular. Cistercienses. Belmonte. Carpetas 1575.16 y 1584.03 .

117. Dos foros de Castiello fechados en la primera mitad del siglo xv. JovelLanos, Melchor Gaspar de: Colección de Asturias, II. Madrid, 1948, documento 245; Fernández Mier, Margarita: Belmonte II, 2001. Documento 158.

118. Mendo Carmona, Concepción: La escritura como vehículo de cultura en el Reino de León (s. IX-X), (Tesis doctoral inédita), Universidad Complutense de Madrid, 1994, pp. 136-137; IDEM: «El pensamiento archivístico medieval...», en Soto RÁbanos, José María (coord.): Pensamiento medieval hispano. Homenaje a Horacio Santiago-Otero, I. Madrid, CSIC, 1998, pp. 604-605. 
Unas veces el escriba anónimo es más parco que otras. La identificación de las entradas de estas «memorias» con los documentos del archivo que conocemos es complicada, pero en algunos casos sí ha sido posible dar con la escritura que figura en este listado ${ }^{\text {I9}}$. Esta mano no dejó su huella sobre la mayoría de escrituras del fondo, pero sí sobre un buen número de ellas.

Estos envoltorios estaban compuestos por una cifra de documentos que podía oscilar entre la veintena hasta prácticamente la treintena; mayor que los legajos que se compondrán en Peñamayor a mediados del siglo XvII ${ }^{\mathrm{I20}}$, pero, en todo caso, una cifra que no tiene nada de especial, sino que es similar a la que tienen otros fajos confeccionados en otros archivos en una misma cronología.

TABLA 1. CONTENIDO DE UNO DE LOS ENVOLTORIOS DE ESCRITURAS DEL ARCHIVO MONÁSTICO

(INICIOS S. XVI)

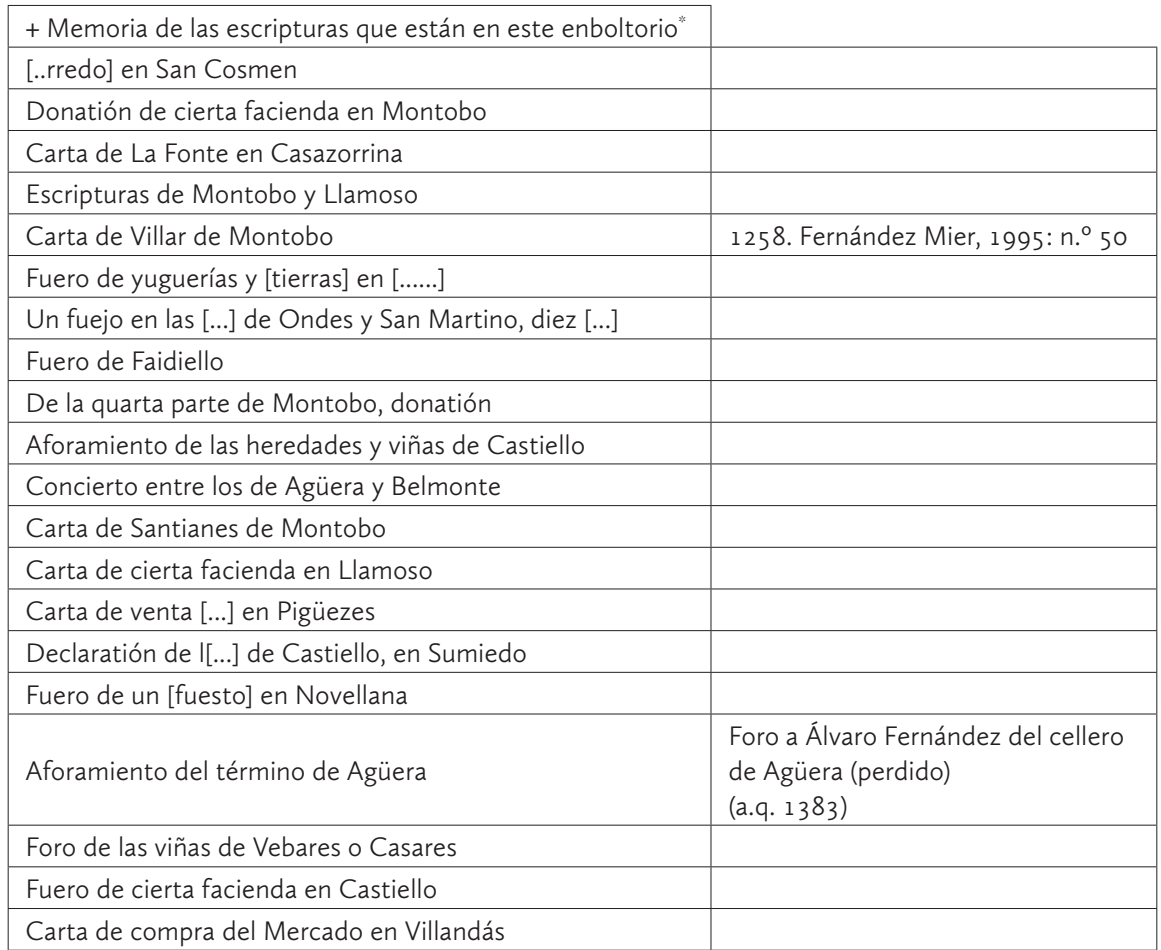

119. Hay que lamentar la práctica total desaparición del papel medieval del archivo monástico, sucedida en el tiempo, pues hay documentos sobre este soporte a los que se les pierde la pista en la Modernidad. Sobre esta cuestión FERnÁNDEZ OrTIZ, Guillermo: Historia y memoria. El monasterio de Belmonte a través de su Tumbo Nuevo, (Tesis doctoral inédita), Universidad de Oviedo, 2017, pp. 555-556.

120. Fernández de Viana y Vieites, José Ignacio: «El archivo del monasterio de Penamayor», Cuadernos de Estudios Gallegos, 87-89 (1974-75), p. 248. 


\begin{tabular}{|c|c|}
\hline Apeo de las viñas de Tineo & $\begin{array}{l}\text { Apeo de los bienes de Tineo (1458) } \\
\text { (perdido) }\end{array}$ \\
\hline $\begin{array}{l}\text { Donatión y confirmatión de Montobo y [juguería] y mytad } \\
\text { de la yglesia de Llamoso }\end{array}$ & $\begin{array}{l}\text { Fernández Mier, 1995: n. }{ }^{\circ} 79 \\
(1268)\end{array}$ \\
\hline Carta del ochavo de San Nicholás de la Riera & $\begin{array}{l}\text { Fernández Mier, 1995: n. }{ }^{\circ} 72 \\
(1267)\end{array}$ \\
\hline Carta de fuero de una juguería de Vigaña y Rastiello & Perdido \\
\hline \multicolumn{2}{|l|}{ Pesquisa de Rastiello } \\
\hline Carta de una tierra en Roçada & Hevia, 1997: n. ${ }^{\circ} 153(1393)$ \\
\hline \multicolumn{2}{|l|}{ Carta de una losa de I[...] } \\
\hline Carta de venta de ciertas [..... en Somiedo & \\
\hline
\end{tabular}

* AHN. Sección Clero. Regular. Cistercienses. Belmonte. Carpeta 1575.16.

\section{I.2.2. La eliminación de documentación: ¿una práctica archivística?}

Una cuestión no exenta de interés y que explica a su vez el valor que el documento escrito tenía para los religiosos del Pigüeña queda puesta de manifiesto a través del tenso enfrentamiento que la institución habría mantenido a mediados del siglo xill con el monasterio de Carracedo, del que había sido filial. La primera referencia conocida que invita a pensar en esta dependencia data de junio II72, cuando según uno de los documentos copiados en el Indicador de Carracedo, el que recoge el acuerdo al que llegan este monasterio y San Claudio de León sobre la obediencia de Toldanos, aparece como confirmante «Dominus Pelagius, abbas de Lapedo» perteneciente al «Carracetensi capitulo» .

En la década de 1240 el conflicto parece hallarse en sus cotas más altas. Si la documentación del cabildo ovetense nos presenta una abadía dependiente del ordinario, la de Carracedo sigue mostrando una abadía sujeta a la casa del Bierzo. En los estatutos de la orden no hay noticia de su desvinculación, aunque sí la hay de Oscos. Creo que puede resultar llamativo que no se conserve en la abadía asturiana ni un solo testimonio de su vinculación a Carracedo, o mejor aún, de su desvinculación. De este proceso hay noticias entre la documentación del cenobio berciano, mientras que en el archivo de la catedral de Oviedo se conserva una espléndida bula de Inocencio IV en la que se da debida cuenta de quién salió triunfante del mismo ${ }^{121}$. ¿Nunca hubo en el archivo de Belmonte documento alguno en el que se recogiera esta filiación? No deja de resultar curioso que, poco más de diez años antes de resolverse el conflicto, en I245 $5^{\mathrm{I} 22}$, el monasterio hubiese cambiado el nombre de Lapedo por el de Belmonte, y que esto hubiese tenido lugar tan solo unos años después de haberse iniciado el proceso de desvinculación de

121. Archivo Catedral de Oviedo (ACO). Serie Plomados. Carpeta 04/o1.

122. La referencia del año 1233 se encuentra en un documento que es copia posterior. SANZ FUENTES, M. ${ }^{a}$ Josefa: «Documentos del monasterio de Belmonte (1231-1263). Catálogo», Asturiensia Medievalia, 6 (1991), p. 181. 
Belmonte y Oscos de Carracedo ${ }^{\mathrm{I2} 3}$. De otro lado, tampoco puede dejar de resultar llamativo, como ha hecho notar María Josefa Sanz para el caso de Valdediós, que sus monjes «olvidasen» al redactar el becerro del siglo xıI su antigua dependencia de Sobrado, aspecto que, en cambio, los monjes de la abadía coruñesa sí tuvieron a bien incorporar a su Tumbo ${ }^{\mathrm{I24}}$.

Por lo tanto, parece que, al menos, hasta los primeros años del siglo xvı, los monjes de Belmonte fueron prestando sucesivas atenciones al archivo.

\section{LA INCORPORACIÓN DE BELMONTE A LA OBSERVANCIA CISTERCIENSE CASTELLANA}

Belmonte sería el último monasterio cisterciense de la Corona de Castilla en incorporarse a la Reforma iniciada por fray Martín de Vargas a comienzos del siglo $\mathrm{XV}^{125}$. Lo hacía definitivamente en enero de 5560 , un siglo más tarde de que se iniciase la expansión de aquella con la anexión de Valbuena de Duero en $1434^{\mathrm{I} 26}$.

El proceso que llevó a la casa asturiana a integrarse en la Congregación cisterciense de Castilla fue relativamente largo, traumático y tormentoso. Más allá del devenir diacrónico, lo cierto es que fueron muchas y diversas las fuerzas que se involucraron, en mayor o menor medida, en un enfrentamiento que se prolongó en el tiempo durante, al menos, diecisiete años. Estos diecisiete años son los de mayor belicosidad, los que se inician en I 543 con la apropiación de la abadía del Pigüeña por parte de la Observancia y que continúan con las reclamaciones del último abad perpetuo de la misma, que se niega a desprenderse de lo que era suyo.

Ahora bien, los anhelos de la Observancia no eran nuevos en esta última fecha, pues, desde al menos el primer cuarto del siglo xvı, son una realidad ampliamente documentada ${ }^{127}$. El contexto es muy claro, ya que Belmonte no constituía entonces particularidad alguna, sino que era uno más de los muchos monasterios norteños (gallegos, campesinos ${ }^{128}$ y asturianos) cuya adhesión a la Congregación estaba

123. Para este último caso vide Álvarez Castrillón, José Antonio: Los Oscos en los siglos X-XIII. Un modelo de organización social del espacio en la Asturias medieval. Oviedo, Ayuntamiento de Santa Eulalia de Oscos, 2001, p. 109.

124. SAnz Fuentes, M. ${ }^{a}$ Josefa: «Falsos y falsificaciones en la documentación medieval», en Munita Loinaz, José Antonio (coord.): Mitificadores del pasado, falsarios de la historia: historia medieval, moderna y de América, 2011. Bilbao, Universidad del País Vasco, pp. 30-31.

125. Martín, Ezequiel: Los bernardos castellanos (Historia de la Congregación cisterciense de Castilla). Palencia, Gráficas Aguado, 1952, p. 29.

126. Entre otros, YÁÑEZ NeIRA, María Damián: «Los primeros usos de la Congregación de Castilla», Compostellanum, XXv1/1-4 (1981), pp. 83 y ss.

127. En 1516 ya se dirigían doña Juana y su hijo Carlos «a todos los corregidores, asystentes, alcaldes e otras justiçias e juezes qualesquier asý del nuestro Prinçipado de Asturias de Oviedo (...)» mandando permitiesen la visita de los monasterios cistercienses por parte del reformador para su corrección y castigo. GARCía Oro, José y PÉREZ LóPEZ, Segundo Leonardo: «La reforma religiosa durante la gobernación del cardenal Cisneros (1516-1518): hacia la consolidación de un largo proceso», Annuarium Sancti lacobi, 1 (2012), p. 115. Documento 40.

128. De Tierra de Campos. 
tratando de conseguir la Observancia cisterciense de Castilla por aquellos años ${ }^{129}$. Es dentro de esta política general donde se enmarca la voluntad del General Reformador de unir la casa asturiana ya en 1525 a la Congregación cuyos designios dirigía.

Y aquí, en este año I525, tropieza con la oposición de dos fuerzas que no van a facilitar la tarea y no van a dar su brazo a torcer, o que, al menos, no lo van a hacer en un primer momento. Por supuesto, está el abad perpetuo de la abadía, fray Julián de Belmonte ${ }^{\mathrm{I} 30}$, que no estaba por la labor de renunciar a su prelacía, a sus derechos heredados y a entregar a los bernardos castellanos la casa que regía, aunque estos estuvieran dispuestos a darle una pensión que le mantuviera durante sus días. No era, este último, ya digo, el objetivo del abad sino que prefería mantener su ascenso y sus preminencias sobre la casa. Y, por otra parte, tampoco el obispo de Oviedo, que entonces era Diego de Muros, estaba dispuesto a permitir que Belmonte se incorporara a la Observancia, entre otras cuestiones porque, en este supuesto, el monasterio quedaría exento de la visita del ordinario ${ }^{\mathrm{I3} \mathrm{I}}$, pues esta se limitaría a la que preceptivamente habría de realizar el General o un visitador comisario en su nombre. El obispo perdería de este modo su control potencial sobre una abadía asentada en la diócesis que gobernaba ${ }^{132}$; por eso colaboró cuanto pudo con el abad perpetuo «mandando a los clérygos de vuestra diócesis diesen todo el fabor e ayuda al abad y monjes del dicho monesterio para ynpedir la dicha reformaçión» ${ }^{133}$.

En este complejo juego de ajedrez, además del abad perpetuo, del obispo de la diócesis de Oviedo y del General de los bernardos castellanos, otras fuerzas se vieron implicadas: de un lado, el emperador Carlos V (y luego su hijo Felipe II) y del otro el pontífice romano. De ninguno de ellos puede decirse que no interviniera con agrado.

El rey participó, ante las peticiones y súplicas del General Reformador, en favor de la adhesión, pero, aún así, el proceso no fue de fácil resolución. El emperador encontró totalmente satisfactorios los procedimientos y objetivos de la

129. En el primer cuarto del siglo xvı se incorporan los monasterios asturianos de Valdediós y Villanueva de Oscos, vide Torné Cubells, Josep: «Origen y presencia de los monjes blancos en Asturias», en VV.AA.: Monasterios cistercienses del Principado de Asturias. [Valdediós], monasterio de Valdediós, 1998, pp. 24-25. Con carácter general: GARCíA Oro, José: Cisneros y la Reforma del Clero español en tiempo de los Reyes Católicos. Madrid, CSIC, 1971, pp. 155-156. Prácticamente idéntico es IDEM: La reforma de los religiosos españoles en tiempo de los Reyes Católicos. Valladolid, Instituto Isabel la Católica, 1969, pp. 106-108. También, PÉrEz-EMBID WAMBA, Javier: Císter en Castilla y León.... Salamanca, Junta de Castilla y León, 1986, pp. 683-696.

130. Vide las páginas que le dedica dentro de su abadologio, GonzÁLEZ GutiÉRrez, Leopoldo: «Aproximación al abadologio de Santa María de Lapedo», Cistercium, 207 (1997), pp. 329-370.

131. Con carácter general vide Barrio Gozalo, Maximiliano: El Clero en la España moderna. Madrid, Caja Sur CSIC, 2010, pp. 323 y ss.

132. «Porque se teme quel obispo de Oviedo o otras personas le pornán algún ynpedimiento en la dicha reformaçión so color que la vesitaçión del abad e monjes del dicho monesterio le perteneçe o so otras colores», GARCíA Oro, José y Portela Silva, M. ${ }^{2}$ José: Los monasterios de la Corona de Castilla en el reinado de Carlos V. Estudio histórico y colección diplomática [Liceo Franciscano, Año LIII]. Santiago de Compostela, El Eco Franciscano, 2001, p. 564. Documento 230.

133. Ibidem, p. 433. Documento 143. 
Observancia ${ }^{\mathrm{I} 34}$ y fue partidario de entregar la abadía a los reformadores, de similar modo al empleado por sus abuelos años atrás y que, en procesos semejantes, no dudaron en favorecer los intereses de estos últimos ${ }^{135}$; intereses que, en última instancia, eran los suyos propios. Así, escribió al obispo, al corregidor, a don Sancho de Miranda (mayorazgo de la casa de Miranda ${ }^{136}$ ) y al propio abad para que favorecieran la reforma ${ }^{\mathrm{I3}}$. A este último, «devoto padre abad del monesterio de Santa María de Belmonte», se le escribía en los siguientes términos: «vos ruego y encargo deys vuestro consentimiento para quel dicho reformador, conforme a las dichas bulas, pueda hazer libremente la dicha reformaçión, tomando con él el medio que sea justo e razonable para que por vuestros días se vos dé alguna pensión por el derecho que teneys a la dicha abadía, como se ha fecho con otros abades» ${ }^{138}$

En esta tesitura, en la que el Reformador presumía de contar con el beneplácito regio y con licencia pontificia, el abad perpetuo, fray Julián, que sabía de las intenciones del emperador, pactaba la entrega de la abadía. Él habría de seguir siendo el abad de Belmonte durante sus días ${ }^{139}$, pero el monasterio se integraba ya en la Observancia; es decir, fray Julian sería su primer abad y, a su muerte, tras él, su sobrino, que entonces era su coadjutor, sería el segundo, aunque también como abad perpetuo ${ }^{\mathrm{I}}$. Solo tras la muerte de ambos entraría el monasterio en esos ciclos trienales que ya iban siendo conocidos aquí y allá por esos años.

Por lo tanto, fray Julián exigía (y se le concedería) seguir como abad, y, además, que la entrada en la Reforma no supusiese una transformación radical del modo de vida que en ella se tenía; es decir, que los monjes que residían en Belmonte no se vieran obligados a introducirse súbitamente en los usos de la Observancia, sino que pudieran mantener sus costumbres en cuestiones de vida, vestimenta y ceremonial. A cambio, fray Julián se comprometía a enviar a su sobrino a uno de los monasterios de la Congregación para formarse en el modo de vivir, de vestirse y en las ceremonias de esta ${ }^{\text {I4I }}$.

En contrapartida, el abad perpetuo accedía a que el Reformador y sus comisarios visitasen la abadía según era preceptivo entre los bernardos castellanos,

134. Ibidem, «Y porque tengo voluntad que asy la dicha casa como todas las otras casas de la dicha horden que hasta agora no están reformadas se reformen y pongan en regular oservançia».

135. En términos similares se expresa SeIJAS Montero, María: «La trayectoria de los monasterios cistercienses del sudoeste gallego desde la Congregación de Castilla», Cuadernos de Historia Moderna, 38 (2013), pp. 76-78.

136. Sobre la casa de Miranda vide CuARTAS Rivero, Margarita: «Investigación del Concejo de Hacienda sobre la familia Miranda de Asturias a finales del siglo XVI», en Población y sociedad en la España cantábrica durante el siglo XVII. Santander, Centro de Estudios Montañeses, 1985, pp. 133-145. Más recientemente DíAz ÁlvareZ, Juan: «Los marqueses de Valdecarzana, señores de vasallos en la Asturias del Antiguo Régimen (siglos XVI-XVIII)», Revista de Historia Moderna, n. ${ }^{\circ} 24$ (2006), pp. 363-394.

137. García Oro, José y Portela Silva, M. ${ }^{a}$ José: Los monasterios de la Corona de.... Santiago de Compostela, El Eco Franciscano, 2001, pp. 434. 565-566. Documentos 144, 231, 233 y 234.

138. Ibidem, pp. 565-566. Documento 232.

139. Ibidem, pp 162-163.

140. «Después de los días de un sobrino suyo que nuestro muy sancto padre le tiene dado por coadjutor en su vida del dicho abbad fray Julian». Ibidem, p. 631. Documento 274.

141. Ibidem, p. 633. Documento 274. 
negándose además a aceptar a otros que no perteneciesen a la Congregación ${ }^{142}$. Eso sí, aquellos visitadores no podrían deponerle, ni tampoco castigarle privándole de la abadía, sino que simplemente él y después su sobrino habrían de actuar de acuerdo a los mandatos de visita. La Observancia solo podría actuar en su contra si se les descubriese vendiendo bienes del monasterio sin licencia del General o viviendo en concubinato ${ }^{\mathrm{I} 43}$.

Otra reclamación no menos importante que hizo fray Julián de Belmonte está relacionada con un privilegio al que no estaba dispuesto a renunciar: que la abadía no perdiese la capacidad de formar a futuros monjes. Era entonces bien sabido que la Observancia, a los monasterios de reciente incorporación, les había ido cercenando la capacidad de dar hábitos, llevando a estas casas monjes formados en los claustros de los institutos reformados, no solo porque estaban educados en un ceremonial y en unos usos que los reformadores avalaban y deseaban extender e imponer, sino también para romper los lazos que pudieran existir entre las élites locales y los monjes de cada cenobio, emparentados como estaban con aquellas ${ }^{\mathrm{I} 44}$. El General únicamente podría enviar monjes a otra abadía y remplazarlos por otros en su lugar en caso de detectar comportamientos inadecuados graves ${ }^{\mathrm{I} 45}$.

Finalmente, el abad perpetuo había de transigir en dos cuestiones trascedentales. En primer lugar, tenía que renunciar a todas las bulas y privilegios de exención de que gozaba hasta la fecha. En segunda instancia debería satisfacer con la Observancia las contribuciones a las que se obligaba a la abadía, y no con otra institución ${ }^{\mathrm{I} 46}$. De hecho, así parece que obraron cuando el obispo de Oviedo les repartió unos cuantos maravedís para contribuir con el subsidio que exigía la corona. El prior de la abadía, fray Gonzalo, en nombre de la comunidad de Belmonte, se dirigía en los siguientes términos al deán y cabildo de Oviedo, por cuanto:

quel dicho monesterio está yncorporado en la oserbanza y prestado obediencia al reformador de la horden de Císter, el qual por su parte y horden, contribuyó aquella cantidá a que fue serbido Su Magestad de mannera que la dicha horden fue y está esclusa de la dicha cuarta y susidio, porque al dicho monesterio no se pueden repartir marabedís algunos; y en caso que le deben de repartir, no se le pueden repartir tamtos marabedís quantos a los otros monesterios, abiendo respeto a la renta que cada uno dellos tiene $(\ldots)^{147}$.

142. Ibidem, p. 632. Documento 274 .

143. Ibidem, p. 631. Documento 274.

144. El último en referirse a esta cuestión, en relación a los monasterios cistercienses asturianos ha sido, ciñéndose al caso de Valdediós, SOLANo Fernández-Sordo, Álvaro: De Maliayo a Villaviciosa. Un territorio de la marina centrooriental de Asturias en la Edad Media. Oviedo, Fundación Cardín - Ayuntamiento de Villaviciosa - Universidad de Oviedo, 2016, passim. Con anterioridad, y a propósito de los monasterios femeninos de la cuenca del Piloña en el tránsito de la Edad Media a la Modernidad, debe destacarse Martínez VeGA, Andrés: Santa María de Villamayor y San Martín de Soto: los monasterios medievales del valle del Piloña. Infiesto, Ayuntamiento de Piloña, 1997.

145. Ibidem, p. 633. Documento 274.

146. Ibidem

147. ACO. Papel suelto. Caja 245, carpeta 22. 
En 1536 moría fray Julián de Belmonte y no parece que haya sido en la vejez. El autor del Tumbo Nuevo nos informa cómo «yendo una vez el abbad don fray Julián a Zezana, a la fiesta de Sant Bartholomé, amaneció muerto otro día» y asegura haber sido informado del particular por algunos que llegaron a alcanzarlo en vida ${ }^{148}$. Le sucedería al frente de la abadía su sobrino, tal y como estaba pactado. Siete años más tarde estallaba el conflicto que se prolongaría por espacio de diecisiete años.

Este episodio es mucho mejor conocido. Uno de lo primeros en dar noticia pública sobre el particular fue Prudencio de Sandoval: «en el año de I543, a cinco días del mes de setiembre, se incorporó con la Congregación de la Observancia, por mandato del emperador Carlos $\mathrm{V} \gg^{\mathrm{I} 49}$. El padre Escudero, que conocía el relato del cronista benedictino, escribiría en el Tumbo Nuevo de Belmonte cómo, en I543, «con la provisión y mandatos de su Real Consejo (...) vino el padre fray Christóval de Horozco, (...) hijo del real monasterio de Valbuena, el qual, trayendo los recaudos necessarios, assí de Roma y del Consejo Real como de la Orden y de nuestro padre general fray Lorenço de Horozco, de La Espina, tomó la posessión deste dicho monasterio (...), siendo (...) abbad don fray Gonçalo de Belmonte, el Segundo, que fue despojado de la abbadía $»^{150}$ y que tuvo que huir para poner su vida a salvo y evitar los castigos, privaciones y censuras que podía inferirle el General Reformador en virtud del oficio ${ }^{\text {I5I }}$.

Fray Gonzalo fue acusado por el presidente de la abadía, el padre Hernando de Salinas, y por el General Reformador de múltiples desmanes, asesinatos ${ }^{152}$, delitos, insultos, injurias y «soltura e mal exemplo de vida e desonestidad del dicho fray Gonçalo e de los religiosos que tenía» ${ }^{153}$, vida relajada ${ }^{154}$, despilfarro de las rentas ${ }^{155} y$ de haber «handado apóstata» ${ }^{156}$. Además, el General aprovechaba la oportunidad para alabar los muchos beneficios espirituales que aportaban los monjes reformados ${ }^{157}$.

El abad expulsado huyó a Roma ${ }^{158}$, donde habría encontrado la colaboración de monjes cistercienses allí asentados ${ }^{159}$. Según anota el padre Escudero, don fray Gonzalo y sus agentes contradijeron en la ciudad eterna cuanto pudieron

\footnotetext{
148. AHA. L. 11308, fol. $7 \mathrm{r}^{\circ}$.

149. Sandoval, Prudencio de: Crónica de Alfonso VII. Madrid, Luis Sánchez, 1600, p. 154.

150. AHA. L. 11308 , fol. $7 \mathrm{r}^{\circ}$.

151. Textualmente leemos cómo al haber huído «no le pudo castigar en su persona conforme a la gravedad e calidad de sus delitos», García Oro, José y Portela Silva, M. ${ }^{a}$ José: Los monasterios de la Corona de Castilla.... Santiago de Compostela, El Eco Franciscano, 2001, pp. 164 y 763.

152. Ibidem, p. 771. Documento 328.

153. Ibidem, p. 773. Documento 328.

154. «Abía ynbiado a besitar el dicho monesterio y por aber allado muy culpado al dicho fray Gonzalo y a causa de la poca religión que abía en el dicho monesterio».

155. «Tener perdida y desipada la dicha casa». Ibidem, pp. 763 y 771 . Documentos 323 y 328.

156. Ibidem, p. 765. Documento 324.

157. Así escribía el presidente Salinas: «se çelebran los divinos ofiçios y el culto divino con mucha reberençia». Ibidem, p. 771. Documento 328.

158. Ibidem, p. 765 . Documento 323.

159. Manrique, Ángel: Annales. Tomo IV. Zamora, Cistercium n. ${ }^{\circ}$ extraordinario, 2010, passim.
} 
la unión definitiva a la Observancia ${ }^{160}$. Supuestamente, según los reformadores, habría acudido a la curia romana y habría obtenido -con falsas informacionessentencias favorables a sus intereses y contrarias a los de los bernardos castellanos.

En Asturias, las reacciones no se hicieron esperar y quienes se manifestaron no debieron de secundar los intereses de los reformadores. Así, en I544, el emperador escribía a su corregidor en la región y a las justicias del reino pasa que se favoreciera la visita al monasterio del padre general Orozco ${ }^{\mathrm{I} 6 \mathrm{I}}$. Además, desde Roma, fray Gonzalo movía los hilos necesarios, aprovechando las muchas amistades y clientelas que dejaba en la comarca en que se hallaba enclavada la abadía ${ }^{162}$.

Por eso, los observantes acudían al rey y, visto el asunto por el Consejo de Castilla, «fue acordado mandar dar esta nuestra carta (...) porque bos mandamos a todos y a cada uno de vos en los dichos vuestros lugares e jurediçiones, según dicho es, que si algunas bulas o letras apostólicas se obieren traído e presentado o truxieren o presentaren por parte del dicho fray Gonzalo de Belmonte (...) sobre lo tocante al dicho monesterio [de Belmonte] (...) no consintais ni deis lugar a que por bertud de las dichas bulas e letras apostólicas (...) se agan autos en perjuiçio de la dicha Reformaçión y Oserbançia (...) ni se tome posesión alguna del dicho monesterio (...) y embiad ante los del nuestro Consejo las dichas bulas e letras apostólicas oreginalmente para que nos las mandemos ber» y para que se actúe en consonancia: si son ciertas se acepte lo contenido en ellas; si se sabe que el Pontífice fue mal informado se le suplique «lo mande prober y remediar como conbenga» ${ }^{163}$.

El asunto se despachaba en el Consejo Real y fray Gonzalo de Belmonte también defendió sus intereses e hizo valer su posición aduciendo que la posesión perpetua de la abadía era suya, no del patronato regio, y que él la habría de tener mientras viviese.

Añadía unas razones de máximo interés que conviene ofrecer en extenso, porque van a permitir mostrar el motivo del desencuentro entre el abad perpetuo y los reformantes:

El dicho don fray Gonçalo tenía el dicho monesterio poblado de religiosos e más reformado que agora estava e más en servicio de Dios Nuestro Señor e quietud e probecho de la casa e nunca se hizo en él cosa de mal exemplo ni desonesto, porque los frayles de la dicha horden han procurado e querían el dicho monesterio por llevarse las rentas dél y anexalle a otras de sus casas para cunplir con poner en él dos o tres religiosos. E porquel dicho su parte no pretendía azer bienes

160. AHA. L. 11308 , fol. 7 v. $^{\circ}$.

161. García Oro, José y Portela Silva, M. ${ }^{a}$ José: Los monasterios de la Corona de Castilla.... Santiago de Compostela, El Eco Franciscano, 2001, p. 762. Documentos 319, 320, 321.

162. Así leemos: Se avía ydo a Roma de donde fatigaba e molestaba a dicho abad y a los otros religiosos del dicho monesterio y enviaba çitaçiones y executoriales así contra ellos como contra los renteros de la dicha casa porque pagavan la renta della, a los quales descomulgava y maltrataban çiertos procuradores y legos y clérigos que tenía (...), los quales fijaban a las puertas del dicho monesterio las çitaçiones y las andavan noteficando a las justiçias y renteros. Ibidem, pp. 771-772. Documento 328.

163. Ibidem, p. 764. Documento 323. 
patrimoniales los del dicho monesterio sino usar de su derecho e posesión e tener en Religión e en servicio de Dios el dicho monesterio el tiempo que biviere ${ }^{164}$.

Niega por lo tanto fray Gonzalo haber incurrido en los graves delitos que los reformadores le imputaban. Es más, se jacta, como los observantes, de ser el monasterio bajo su prelacía un ejemplo de vida en Religión. Sin embargo, lo más significativo del pasaje es precisamente todo lo demás, como vamos a ver a continuación, porque el abad fray Gonzalo no habrá sido un dechado de virtudes pero, desde luego, sabía lo que había y el futuro que los bernardos castellanos tenían pensado para el monasterio que él regía.

Incapaz de hacer valer en la Península sus intereses, fray Gonzalo cederá todo su derecho sobre la abadía al Pontífice que hará precisamente aquello que los reformadores más criticaban: hacerle entrega del monasterio, bajo el régimen de la encomienda, a Pedro Gómez de Villarroel, que, no obstante, no aceptaría ${ }^{165}$. Finalmente, el Reformador le pedirá al Papa que la una a la Congregación a lo que, en última instancia, accederár ${ }^{166}$. Escribe Sandoval: «Y en el año de 1560 , a 27 de enero, el papa Paulo IV dio la bula desta unión ${ }^{167}$.

Por su parte, fray Gonzalo, el abad desposeído, acabaría sus días en la marginalidad: habiendo los bernardos castellanos hecho correr la voz de ser monje prófugo, y de tener que ser estos recluídos en los monasterios en virtud de resolución pontificia, trató de prenderle un alguacil del corregidor cuando se hallaba residiendo en el vecino concejo de Grado. Aquel día, con ayuda de familiares y deudos, organizó una escaramuza que originó cierta inquietud entre los reformadores, que comunicaron el asunto en el Consejo de Castilla ${ }^{168}$.

Solo tras este largo proceso, I7 años después de que Carlos V adjudicase a los reformadores la casa asturiana, el papa Pablo IV conseguía unir «este monasterio de Nuestra Señora de Belmonte a la Regular Observancia de España de nuestra sagrada orden de Císter e instituto de nuestro padre Sant Bernardo ${ }^{169}$. Entraba así la casa asturiana en la modernidad y lo hacía traumáticamente.

¿Cómo se resintió el archivo?, baste decir que no conocemos mención a ningún documento pontificio anterior al año I560 y que nada queda en el archivo en este sentido. Sabiendo lo copioso que es el número de documentos pontificios en otras abadías y valorando justamente el estimable volumen documental medieval en donaciones, compras, foros... y especialmente la rica serie de privilegios regios que se conservan del archivo de Belmonte ${ }^{\mathrm{I70}}$, la pérdida total del documento pontificio

\footnotetext{
164. Ibidem, p. 774. Documento 328.

165. MANRIQUe, Ángel: Opus cit., p. 35.

166. Ibidem.

167. Sandoval, Prudencio de: Crónica de Alfonso VII. Madrid, Luis Sánchez, 1600, p. 154.

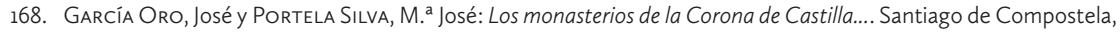
El Eco Franciscano, 2001, p. 167.

169. AHA. L. 11308 , fol. $7 v^{\circ}$.

170. Ha desgranado el contenido del archivo, Fernández OrTIZ, Guillermo: Historia y memoria. El monasterio..., (Tesis doctoral inédita), Universidad de Oviedo 2017, pp. 275-278.
} 
medieval, que no dejará ni una sola noticia en los instrumentos de época moderna, solo puede explicarse por un proceso de semejante envergadura.

\section{II.1. EL DESMANTELAMIENTO DE LA ABADÍA. PROYECTOS FALLIDOS}

Como hemos anotado, a comienzos de la década de I540 fray Gonzalo de Belmonte se quejaba ante el Consejo de Castilla que los reformadores pretendían suprimir la categoría abacial de Belmonte, reduciendo el centro a un sencillo priorato, integrado apenas por dos o tres religiosos y dependiente de otra casa a la que se habrían de dirigir las rentas que se sacasen de los bienes del cenobio asturiano. Esto atentaba contra sus intereses y derechos sobre la abadía, evidentemente. Veremos ahora qué había de verdad en ello.

Desde luego, la Reforma supuso, especialmente en el Noroeste peninsular, la reestructuración del mapa conventual. No solo los bernardos, también los benedictinos de la congregación de San Benito el Real, modificaron la categoría de las distintas abadías y jerarquizaron internamente la relación entre unas y otras ${ }^{171}$. Pequeños centros perdían su activa vida comunitaria y el rango abacial, quedando reducidos a pequeños prioratos en los que apenas uno o dos religiosos residirían para controlar las posesiones, sacar las rentas y encargarse de dirigirlas a las casas de las que entonces pasaban a depender ${ }^{172}$.

Además de la reestructuración del panorama existente, los reformadores no dejaron de plantear la erección de nuevos establecimientos, especialmente en medios urbanos. No solo contemplaron levantar monasterios en los núcleos principales del país (Valladolid ${ }^{173}$, Madrid ${ }^{174}$ o Santiago, ya en el siglo XVIII ${ }^{175}$ ) sino también colegios vinculados a centros universitarios, en los que los profesos de la Congregación pudieran recibir unas enseñanzas acordes a los nuevos tiempos.

Ya a inicios del siglo xvı habían abierto los bernardos castellanos un colegio en Salamanca para que en la Universidad de la ciudad del Tormes pudieran estudiar quienes vistieran el hábito blanco de la Congregación ${ }^{176}$. Tuvo efímera existencia y entre I53I y 534 los bernardos acordaron trasladarlo a Alcalá.

171. En la diócesis de Lugo esta reestructuración fue aún más significativa, según REY CASTELAO, Ofelia: «El Clero Regular», en GARCíA Oro, José (dir.): Historia de las diócesis españolas. 15. Iglesias de Lugo, Mondoñedo-Ferrol y Orense. Madrid, Biblioteca de Autores Cristianos, 2002, p. 137.

172. Ha estudiado las posibilidades económicas de estos prioratos, aunque focalizando su mayor interés en el siglo XVIII, Seijas Montero, María, «Los prioratos de Santa María de Oia en el sudoeste gallego y en el noroeste portugués a fines de la Edad Moderna: aproximación a su situación económica», Hispania Sacra, n. ${ }^{138}$ (2016), pp. 675-691.

173. MAnRIQUe, Ángel: Opus cit., p. 39.

174. Tras diversos intentos se fundará a fines del siglo xvı. Un estudio sobre el mismo, con análisis del período fundacional en Yã̃̃ez NeIRA, María Damián: «Monasterio de Santa Ana de Madrid. 1596-1996)», Cistercium, 209 (1997), pp. 735-774.

175. Da la noticia Rey CASTELAO, Ofelia: Libros y lectura en Galicia. Siglos XVI-XIX. Santiago de Compostela, Xunta de Galicia, 2003, p. 381 .

176. Según García Oro, en 1505 se acometió la empresa de construir un colegio en Alcalá; en Salamanca el proyecto 
Sufragar su mantenimiento era difícil pues, en principio, no contaba el centro de enseñanza con un volumen patrimonial de entidad. Por esto, los reformadores van a obtener del Papa, «para sustento de los monjes que estudiasen en él y de sus sirvientes», licencia para unir al colegio de Salamanca los monasterios de Acebeiro, Peñamayor y San Miguel de Dueñas ${ }^{177}$. De este modo, estos centros perdían la categoría de abadías y destinaban a partir de entonces sus rentas no al mantenimiento de una copiosa comunidad, sino al sostenimiento del nuevo centro formativo. Insuficientes estas rentas para su mantenimiento, en I523 se añadieron las de A Franqueira que dejó también de ser abadía ${ }^{178}$, mientras San Miguel, que se convirtió en abadía femenina, quedó comprometida a la satisfacción anual de un elevado número de maravedís para con el colegio salmanticense primero, con el complutense después ${ }^{179}$.

Trasladado el colegio a su nuevo destino, no faltaron voces a inicios de la década de 1540 que confiaban en que Salamanca recuperase el instituto perdido o, en su defecto, se fundase en la ciudad castellana un nuevo centro de estudios ${ }^{180}$.

Es en este contexto en el que -de creer a fray Gonzalo- debió de plantearse la supresión de la dignidad abacial en Belmonte y anexar las rentas extraídas de la casa asturiana a otro instituto. De hecho, años más tarde, en la década de 1580 , con Belmonte ya plenamente incorporado a la Observancia, cuando los bernardos castellanos sigan queriendo levantar un colegio a orillas del Tormes dotado con las rentas suficientes, algunas voces van a plantear la transformación de la abadía asturiana en un pequeño priorato dependiente del nuevo centro de enseñanza ${ }^{181}$. Varios miembros en el seno de la Congregación prentenderán eliminar la dignidad abacial en Belmonte, transformando el viejo establecimiento en un priorato dependiente del colegio que la Observancia funda en Salamanca, integrado únicamente por dos religiosos con un prior al frente ${ }^{\mathrm{r82}}$. En este contexto,

hubo de esperar hasta 1514, GARCíA ORO, José: La Reforma de los religiosos españoles.... Valladolid, Instituto Isabel la Católica, 1969, p. 110.

177. Sobre la incorporación de Acebeiro, vide Seijas Montero, María: «La trayectoria de los monasterios cistercienses...», Cuadernos de Historia Moderna, 38 (2013), p. 76.

178. Al margen de los estudios de caracter general pueden verse, LIMIA GARDón, Francisco Xavier: «Santa María de A Franqueira», en YÁÑEz NeIRA, María Damián (coord.): Monasticón cisterciense gallego, I. León, Edilesa, 2000, pp. 274-275; Redondo CANTERA, María José: «Apuntes para la historia del desaparecido convento de San Bernardo en Salamanca: su edificio», Boletín del Seminario de Estudios de Arte y Arqueología, 56 (1990), p. 438. También, SEIJAS MONTERO, María: «Aproximación a la actividad económica del monasterio cisterciense de Santa María de A Franqueira en la época moderna», en CASAL, Raquel, ANDRADE, José Miguel y LóPEZ, Roberto J. (eds.): Galicia monástica. Estudos en lembranza da profesora María José Portela Silva. Santiago de Compostela, Universidad de Santiago de Compostela, 2009, pp. 247-248.

179. Sobre los pagos de San Miguel al colegio de Salamanca se conserva documentación. Vide Cavero Domínguez, Gregoria: Catálogo del fondo monástico de San Miguel de Dueñas. León, Universidad de León, 1994, pp. 68-69 y 72.

180. Ofrece la noticia Manrique, Ángel: Op. Cit., p. 178. La recoge también Redondo Cantera, María José: «Apuntes para la historia del desaparecido...», Boletín del Seminario de Estudios de Arte y Arqueología, 56 (1990), p. 439.

181. Manrique Ángel: Op. cit., pp. 77-78 y 81. También Paz GonzÁlez, Daniel de: El monasterio de Santa María de Villanueva de Oscos. De la Reforma a la exclaustración. Oviedo, Universidad de Oviedo, p. 25.

182. AHN. Sección Clero. Regular. Cistercienses. Valbuena de Duero. Libro L. 16621, folio 74 r.. 
las rentas no irían encaminadas al sustento de una comunidad monástica sino al centro formativo creado en la ciudad del Tormes ${ }^{183}$.

Pese a estas pretensiones, Belmonte no llegaría a perder la categoría de abadía, si bien la imagen, en el cuarto final de la centuria, era la de una casa pequeña. Pequeña era para los miembros de la Congregación por los escasos niveles de ingresos que tenía ${ }^{184}$, pero también por el bajo número de religiosos que sustentaba ${ }^{185}$. La imagen que ofrecían los forasteros no difería de la opinión que corría entre los propios bernardos. En la década de i570, Morales no dudaba en afirmar que era «casa pequeña de císter en Asturias» ${ }^{186}$, mientras que años después Sandoval se referiría a Belmonte como «honrado monasterio, aunque de los menores que esta sancta Congregación [cisterciense] tiene ${ }^{187}$.

Todos los vaivenes que hemos señalado afectaron, que duda cabe, al normal funcionamiento de la vida monástica y, por ende, a las labores administrativas, con lo que esto debió de suponer de desatención al archivo. Había intereses más inminentes que la vigilancia continua del patrimonio fundiario y la correcta percepción de la renta agraria.

En fin, en vísperas de la Reforma el fondo distó de estar en el lamentable estado que dibujaría Escudero hacia I584. Tal imagen, hubo de obedecer a los avatares de esta dura etapa de tránsito que acabo de referir, pues los monjes del medievo y del primer cuarto del siglo xvı no descuidaron la conservación y la descripción de sus escrituras.

\section{CONCLUSIONES}

Este era, pues, el valor que los documentos podían tener para los bernardos del Pigüeña. Durante toda la Edad Media, la guarda y conservación de las escrituras tocantes a sus intereses fue una preocupación constante para los religiosos asentados en Belmonte, como preocupación constante fue la puesta por escrito de sus negocios y de sus bienes. Hubo pérdidas casuales, salidas y, por qué no, hay que imaginar destrucciones voluntarias, pero los monjes procuraron evitar la pérdida masiva de documentación. Hicieron copias simples de sus documentos y luego traslados autorizados ante notario, iniciaron la confección de un cartulario, y no

183. Redondo Cantera, María José: «Apuntes para la historia del desaparecido...», Boletín del Seminario de Estudios de Arte y Arqueología, 56 (1990), pp. 439-441.

184. Difiniciones cistercienses, 1561 , fol. $22 \mathrm{v}^{\circ}$.

185. Manrique, Ángel: Op. cit., p. 258.

186. Morales, Ambrosio de: Viage por orden del rey don Phelipe II a los reynos de León y Galicia y Principado de Asturias, para reconocer las Reliquias de Santos Sepulcros reales y libros manuscritos de las cathedrales y monasterios. Madrid, Antonio Marín, 1765, p. 113.

187. Sandoval, Prudencio de: Crónica de Alfonso VII. Madrid, Luis Sánchez, 1600, p. 154. 
dudaron en pasar del papel al pergamino aquellos instrumentos que les merecían mayor estima, como era el caso de los otorgados por los monarcas.

El monasterio fue desde el siglo xıII lugar de escrituración y los monjes se procuraron, especialmente en los dos primeros tercios de la centuria, sus propias escrituras. Al mismo tiempo (desde, al menos mediados de siglo) se habilitó una estancia o espacio para el depósito de la documentación, que posiblemente no haya distado de lo que conocemos para otras abadías cistercienses. En el siglo xv este espacio aparace designado bajo la voz «cartolario» y en él, ya entrado el siglo xvı, se hallaban las escrituras en envoltorios de una treintena de piezas cada una, más o menos descritas, aunque, sin embargo, sin un orden aparente.

El difícil proceso de integración de Belmonte en la Congregación cisterciense de Castilla y las disputas entre los últimos abades perpetuos y los monjes reformadores constituyó una etapa de profunda depresión para la institución y, paralelamente, tanto el estado del archivo como la entrada de nueva documentación debieron de resentirse. Además, algunos instrumentos debieron de movilizarse entonces para apoyar la causa de unos u otros, o, sencillamente, de destruirse. Esto es lo que debió de suceder con la documentación pontificia, cuya ausencia contrasta con la entidad del fondo medieval en pergamino. Del mismo modo, el volumen de documentación en papel para los últimos años del medievo y la primera mitad del siglo xvı es mínimo.

En fin, la imagen de archivo totalmente desarticulado, perteneciente a unos monjes que ignoraban su valor y su contenido, que ofrecía el padre Escudero tras su llegada al monasterio en I58I, respondía, por lo tanto, más a los avatares relacionados con su incorporación a la Observancia cisterciense castellana que a una situación estructural. 


\section{BIBLIOGRAFÍA}

AlLEN, Richard: «À la recherche d'un atelier d'écriture de la Normandie cistercienne: le scriptorium de l'abbaye de Savigny ( $\mathrm{XII}^{\mathrm{e}}$-XIII ${ }^{\mathrm{e}}$ siècle)», en BaUdin, Arnaud y Morelle, Laurent (dirs.): Les pratiques de l'écrit dans les abbayes cisterciennes (XII ${ }^{e}$-milieu du XVI ${ }^{e}$ siècle). Produire, échanger, contrôler, conserver. Paris, Somogy Éditions d'art, 20I6, pp. 3I-54.

Álvarez Castrillón, José Antonio: Colección diplomática del monasterio de Santa María de Villanueva de Oscos (II39-I30o). Oviedo, RIDEA, 20 II.

Álvarez Castrillón, José Antonio: El monasterio de Santa María de Villanueva de Oscos. Historia y fuentes. Oviedo, Ayuntamiento de Villanueva de Oscos, 2010.

Álvarez CASTrillón, José Antonio: El monasterio de Villanueva de Oscos. Guía didáctica. Oviedo, Ayuntamiento de Villanueva de Oscos, 20 Io.

Álvarez CaStrillón, José Antonio: Los Oscos en los siglos X-XIII. Un modelo de organización social del espacio en la Asturias medieval. Oviedo, Ayuntamiento de Santa Eulalia de Oscos, 200I.

ANTUÑa CASTRO, Roberto: Notariado y documentación notarial en el área central del señorío de los obispos de Oviedo (I29I-I389), (Tesis doctoral inédita), Universidad de Oviedo, 2014.

Ayala Martínez, Carlos: Libro de privilegios de la orden de San Juan de Jerusalén en Castilla y León (siglos XII-XV). Madrid, Instituto complutense de la orden de Malta, 2005.

Azevedo Santos, María José: «Os «clérigos-notários» em Portugal (séculos XI-XII)», Estudos de diplomática portuguesa. Lisboa, Collibri-Universidade Coimbra, 200I, pp. 75-9I.

BAlboA DE PAz, José Antonio: El monasterio de Carracedo. León, Instituto Leonés de Cultura, 2005 (2. ${ }^{\mathrm{a}}$ edición).

BARRET, Sébastien: La mémoire et l'écrit: l'abbaye de Cluny et ses archives, $X^{e}$-XVIII ${ }^{e}$. Münster, Lit VerlaG, 2004.

Barrio Gozalo, Maximiliano: El Clero en la España moderna. Madrid, Caja Sur - CSIC, 2 oio.

BAUDIN, Arnaud: «Sceller à Clairvaux et dans sa filiation champenoise du Xı1 au $\mathrm{Xv}^{\mathrm{e}}$ siècle», en Baudin, Arnaud, Dohrmann, Nicolas y Veyssière, Laurent (dirs.): Clairvaux l'aventure cistercienne. Paris, Somogy Éditions d'art, 2015, pp. I73-183.

Blasco, Rosa María: Una aproximación a la institución notarial en Cantabria. Santander, Universidad de Cantabria, I990.

BULLIMORE, Katherine: «Folcwin of Rankweil: the world of a Carolingian local official», Early Medieval Europe, I3 (2005), pp. 43-77.

CAlleja Puerta, Miguel: «A escribir a la villa. Clerecía urbana, escribanos de concejo y notarios públicos en la Asturias del siglo xıI», Historia. Instituciones. Documentos, 42 (2015), pp. 59-82.

CAlleja Puerta, Miguel: «Archivos dispersos, fuentes reencontradas. Notas metodológicas al estudio de las élites del reino de León en los siglos centrales de la Edad Media», Medievalismo, I2 (2002), pp. 9-36.

CAlleja Puerta, Miguel: «Cartularios y construcción de la memoria monástica en los reinos de León y Castilla durante el siglo Xiı», en LAMAzou-Duplan, Véronique y RAmírez VAQUero, Eloísa (dirs.): Los cartularios medievales. Escribir y conservar la memoria del poder, el poder de la memoria. Pau, Universidad de Pau, 2013, pp. I87-I97.

CAlleja Puerta, Miguel: «Certezas y dudas sobre la tradición textual del fuero de Avilés de II55", Revista de Filoloxía Asturiana, 9-Io (2009-Io), pp. 215-226. 
CAlleja Puerta, Miguel: «El fuero de Avilés de ir55, original extracancilleresco de Alfonso VII», en Ruiz de la PeÑa Solar, Juan Ignacio, Sanz Fuentes, María Josefa, y Calleja Puerta, Miguel (coords.): Los fueros de Avilés y su época. Oviedo, RIDEA, 20I2, pp. 44I-442.

Calleja Puerta, Miguel: «La Asturias medieval», en Fernández Pérez, Adolfo y Friera SuÁrez, Florencio (coords.): Historia de Asturias. Oviedo, KRK, 2005, pp. I5I-34I.

Calleja Puerta, Miguel: «La Catedral de Oviedo como centro de conservación de documentos en la Alta Edad Media», Estudos em homenagem ao Professor Doutor José Marques, IV. Oporto, Universidad de Porto, 2006, pp. I79-I9I.

CAlleja Puerta, Miguel: «Señores sin cancillería. Génesis y validación de los documentos de la aristocracia castellano-leonesa (IIOO-I250 ca.)», en SUÁrEz GonZÁlEz, Ana (ed.): Escritura y Sociedad: la nobleza. Santiago de Compostela, Universidad de Santiago Xunta de Galicia, 2017, pp. 19-58.

Calleja Puerta, Miguel: El conde Suero Vermúdez, su parentela y su entorno social. La aristocracia asturleonesa en los siglos XI y XII. Oviedo, KRK, $200 \mathrm{I}$.

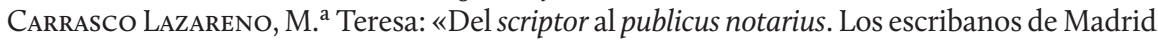
en el siglo xIII», Espacio, Tiempo y Forma. Serie 111. Historia Medieval, I6 (2003), pp. I87-344.

Carrasco Lazareno, M. ${ }^{\mathrm{a}}$ Teresa: La documentación de Santo Domingo el Real de Madrid (I286-I4I6). I. Estudio Documental, (Tesis doctoral inédita), Universidad Autónoma de Madrid, I994.

Cavero Domínguez, Gregoria: Catálogo del fondo monástico de San Miguel de Dueñas. León, Universidad de León, I994.

Cavero Domínguez, Gregoria: Colección documental del monasterio de Nogales (II49-I498). León, Centro de Estudios San Isidoro, 20oI.

Cavero Domínguez, Gregoria: El esplendor del Císter en León. León, Fundación VascoHullera, 2007.

CHASTANG, Pierre: «Cartulaires, cartularisation et scripturalité médiévale: la structuration d'un nouveau champ de recherche», Cahiers de Civilisation Médiévale, 49 (2006), pp. 2I-3I.

COCHERIL, Maur: Etudes sur le monachisme en Espagne et au Portugal. Paris, Societé d'editions Les Belles Lettres, I966.

Cruz Herranz, Luis Miguel: «El archivo monástico. Entre la gestión de su administración y la gestión de su memoria histórica», en BALDAQUí EsCANDELL, Ramón (ed.): Lugares de escritura: el monasterio. Alicante, Universidad de Alicante, 2016, pp. I77-230.

Cunha Alegre, Maria Cristina Almeida e: «Tabeliães bracarenses no século xilı», IX Centenário da dedicação da sé de Braga. Congresso Internacional, Braga, I990, pp. 249-265.

Cunha Alegre, Maria Cristina Almeida e y Silva, Maria Joao: «Cooperazione e coesistenza tra professionisti della scrittura: tabellioni pubblici e notai vescovili (Braga e Porto - sec. xill-XIV)», en Musco, Alessandro y Musotto, Giuliana (eds.): Coexistence and cooperation in the middle age. Palermo, Officina di Studi Medievali, 20I4, pp. 445-452.

ERHART, Peter: «Carta ista amalfitana est et nescitur legere. The charters of Cava dei Tirreni and their evidence for early medieval archival practice», Gazette du livre medieval, 50 (2007), pp. 27-39.

Escalona Monge, Julio: «Antes de los cartularios: gestión de archivos y transmisión de los documentos de la Castilla condal (siglo IX-I038)», en SiRANToine, Hélène, y Escalona Monge, Julio (coords.): Chartes et cartulaires comme instruments de pouvoir: Espagne et Occident chrétien ( VIII $^{e}$-XII ${ }^{e}$ siècles). Madrid, CSIC - Universidad de Toulouse, 20I3, pp. I47-I67.

FERNÁNDEZ CONDE, Francisco Javier: «Influencias foráneas y transformación de la sociedad asturiana a lo largo del siglo Xıı», Asturiensia Medievalia, 5 (I986), pp. III-I33. 
Fernández Flórez, José Antonio y Herrero de la Fuente, Marta: Colección documental del monasterio de Santa María de Otero de las Dueñas. II (IIO9-I300). Índices. León, Centro de Estudios e Investigación San Isidoro - Caja España de Inversiones - Archivo Histórico Diocesano, 2005.

FERnÁNDEZ Flórez, José Antonio: La elaboración de los documentos en los reinos hispánicos occidentales (sS. XI-XIII). Burgos, Institución Fernán González, 2002.

Fernández Mier, Margarita: «Economía y sociedad en Miranda y Somiéu en los siglos X-XIII», Asturiensia Medievalia, 8 (1995-96), pp. III-I32.

Fernández Mier, Margarita: Documentos del monesteriu de Balmonte (sieglos XIV y XV). Oviedo, Academia de la Llingua Asturiana, 20or.

FernÁndez Mier, Margarita: Documentos del Monesteriu de Balmonte (sieglu XIII). Oviedo, Academia de la Llingua Asturiana, I995.

FERNÁNDEZ OrTIZ, Guillermo: «La práctica notarial en el concejo de Grado (Asturias) durante el siglo xilı. De los escribanos rurales al notariado público», en Pueyo Colomina, Pilar (coord.): Lugares de escritura: la ciudad. Zaragoza, Institución Fernando el Católico, 20I5, pp. I7I-I87.

FERnÁNDEZ OrTiz, Guillermo: Historia y memoria. El monasterio de Belmonte a través de su Tumbo Nuevo, (Tesis doctoral inédita), Universidad de Oviedo, 2017.

Floriano Cumbreño, Antonio C.: Colección diplomática del monasterio de Belmonte, Oviedo, IDEA, I960.

García Larragueta, Santos Agustín: Colección de documentos de la catedral de Oviedo. Oviedo, IDEA, I962.

García Luján, José Antonio: Cartulario del monasterio de Santa María de Huerta. Soria, Monasterio de Huerta, I98I.

García Oro, José y Pérez López, Segundo Leonardo: «La reforma religiosa durante la gobernación del cardenal Cisneros (1516-1518): hacia la consolidación de un largo proceso», Annuarium Sancti Iacobi, I (2012), pp. 47-I74.

García Oro, José y Portela Silva, M. ${ }^{\mathrm{a}}$ José: Los monasterios de la Corona de Castilla en el reinado de Carlos V. Estudio histórico y colección diplomática [Liceo Franciscano, Año LIII]. Santiago de Compostela, El Eco Franciscano, 200I.

García Oro, José: Cisneros y la Reforma del Clero español en tiempo de los Reyes Católicos. Madrid, CSIC, I97I.

García Oro, José: La reforma de los religiosos españoles en tiempo de los Reyes Católicos. Valladolid, Instituto Isabel la Católica, I969.

Gomes, Saúl António: «Sigillis abbatis et conventus muniantur. A Sigilografía Cisterciense Medieval em Portugal», Signum, 9 (2007), pp. 9-52.

Gomes, Saul António: In Limine conscriptionis. Documentos, chancelaria e cultura no mosteiro de Santa Cruz de Coimbra (séculos XII a XIV). Viseu, CHSC, 2007.

GonZÁlez GutiérReZ, Leopoldo: «Aproximación al abadologio de Santa María de Lapedo», Cistercium, 207 (1997), pp. 329-370.

GonZález Hymla, Herbert: El monasterio de Piedra. Fuentes y documentos. Madrid, Real Academia de la Historia - Institución Fernando el Católico, 2014.

Guyotjeannin, Olivier: «La science des archives a Saint-Denis (fin du XIII ${ }^{\mathrm{e}}$-debut du XvI ${ }^{\mathrm{e}}$ siécle)», en Autrand, Françoise, Gauvard, Claude, y Moeglin, Jean-Marie (coord.): Saint-Denis et la Royauté. Études offertes à Bernard Guenée. Paris, Publications de la Sorbonne, I999, pp. 35-50. 
Herráez Ortega, M. ${ }^{a}$ Victoria: «Soberanos, señores y damas. Los promotores del Císter en el Reino de León», en CAvero Domínguez, Gregoria y Celis Sánchez, Jesús (coords.): El Císter en el Reino de León. León, Instituto Leonés de Cultura, 20I2, pp. 2I-33.

Hevia Ballina, Agustín: «Un inventario de documentos que formaron parte del archivo del monasterio cisterciense de Santa María de Lapedo en Belmonte», Studium Ovetense, 20 (1997), pp. 69-94.

INNES, Matthew: «On the material culture of legal documents: charters and their preservation in the Cluny archive, ninth to eleventh centuries», en Brown, Warren, Costambeys, Marios, Innes, Matthew, y Kosto, Adam (eds.): Documentary Culture and the Laity. Cambridge, Cambridge University Press, 2013, pp. 290-30I.

Kosto, Adam: «Sicut mos esse solet: documentary practices in Christian Iberia, c. 70oiooo», en Brown, Warren, Costambeys, Marios, Innes, Matthew, y Kosto, Adam (eds.): Documentary Culture and the Laity. Cambridge, Cambridge University Press, 2013, pp. 259-282.

Lucas Álvarez, Manuel: «La Cancillería de Alfonso IX (II88-I230)», El reino de León en la Alta Edad Media v. Las Cancillerías Reales (IIO9-I230). León, Centro de Estudios San Isidoro - Archivo Histórico Diocesano de León - Caja España, I993.

Martín López, M. ${ }^{a}$ Encarnación: «Colección diplomática de la infanta doña Sancha (III8II59). Estudio Crítico», en VV.AA.: León y su Historia. Miscelánea Histórica. VIII. León, Centro de Estudios e Investigación San Isidoro - Caja de España - Archivo Histórico Diocesano de León, 2003, pp. 139-345.

Martínez Martínez, Martín: Cartulario de Santa María de Carracedo (992-I500). I. $992-$ I274. León, Instituto de Estudios Bercianos, I997.

Mendo Carmona, Concepción: «El pensamiento archivístico medieval. Una página de la historia de la cultura a través del fondo documental de la catedral de León», en Soto Rábanos, José María (coord.): Pensamiento medieval hispano. Homenaje a Horacio Santiago-Otero, I. Madrid, CSIC, I998, pp. 59I-623.

Mendo CARmona, Concepción: «Los tumbos medievales desde la perspectiva archivística», en VV.AA.: Jornadas científicas: documentación jurídico-administrativa, económico financiera y judicial en el reino castellano-leonés (s. X-XIII). Madrid, Universidad Complutense, 2002, pp. I65-189.

Mendo Carmona, Concepción: La escritura como vehículo de cultura en el Reino de León (s. $I X-X)$, (Tesis doctoral inédita), Universidad Complutense de Madrid, I994.

NuÑEz Contreras, Luis: «Colección diplomática de Vermudo III, rey de León», Historia. Instituciones. Documentos, 4 (1977), pp. 38I-5I4.

Paredes Naves, M. a Concepción: «El archivo del monasterio de Santa María de Belmonte, especial referencia al Tumbo Nuevo», en Rodríguez Álvarez, Ramón (coord.): Pasión por Asturias. Estudios en homenaje a José Luis Pérez de Castro. Oviedo, Real Instituto de Estudios Asturianos, 2013, pp. 823-839.

Pérez-Embid Wamba, Javier: El Císter en Castilla y León. Monacato y dominios rurales (siglos XII-XV). Salamanca, Junta de Castilla y León, I986.

Rey Castelao, Ofelia: «El Clero Regular», en García Oro, José (dir.): Historia de las diócesis españolas. I5. Iglesias de Lugo, Mondoñedo-Ferrol y Orense. Madrid, Biblioteca de Autores Cristianos, 2002, pp. I37-I49.

Rey Castelao, Ofelia: Libros y lectura en Galicia. Siglos XVI-XIX. Santiago de Compostela, Xunta de Galicia, 2003.

SÁEz SÁNCHEZ, Carlos: «Códices diplomáticos y conservación documental», Acta historica et archaeologica mediaevalia, 25 (2003-04), pp. 83I-848. 
SÁEz SÁNchez, Carlos: «Origen y función de los cartularios hispanos», Gazette du livre médiéval, 46 (2005), pp. 37-48.

SAnz Fuentes, M. ${ }^{a}$ Josefa: «Documentos del monasterio de Belmonte (I23I-I263). Catálogo», Asturiensia Medievalia, 6 (1991), pp. I77-203.

SAnZ Fuentes, M. ${ }^{\mathrm{a}}$ Josefa: «El documento de Fakilo (803): estudio y edición», Estudos em homenagem ao Professor Doutor José Marques, IV. Oporto, Universidad de Porto, 2006, pp. 3I-40.

SANZ Fuentes, M. ${ }^{a}$ Josefa: «El monasterio de Valdediós, espacio para la escritura», Mosteiros Cistercienses. Actas do Congresso Internacional realizado em Alcobaça nos días I4 a I7 de junho de 20I2, III. Alcobaça, 2013, pp. 205-218.

SAnZ Fuentes, M. ${ }^{a}$ Josefa: «Estudio paleográfico», en VV.AA.: Liber Testamentorum Ecclesiae Ovetensis. Barcelona, Moleiro, I995, pp. cxvil-cxxxil.

SANZ Fuentes, M. ${ }^{a}$ Josefa: «Falsos y falsificaciones en la documentación medieval», en Munita Loinaz, José Antonio (coord.): Mitificadores del pasado, falsarios de la historia: historia medieval, moderna y de América, 20Ir. Bilbao, Universidad del País Vasco, pp. I7-32.

Sanz Fuentes, M. ${ }^{a}$ Josefa: El Tumbo Negro de la Catedral de Astorga. Aproximación a su historia. Astorga, Centro de Estudios Astorganos Marcelo Macías, 20 Io.

Sanz Fuentes, M. ${ }^{a}$ Josefa: La reescritura del pasado. El Liber testamentorum de la catedral de Oviedo. Oviedo, Universidad de Oviedo, 2014

Seijas Montero, María: «Los prioratos de Santa María de Oia en el sudoeste gallego y en el noroeste portugués a fines de la Edad Moderna: aproximación a su situación económica», Hispania Sacra, n. ${ }^{\circ}$ I38 (2016), pp. 675-69I.

Seijas Montero, María: «Aproximación a la actividad económica del monasterio cisterciense de Santa María de A Franqueira en la época moderna», en CASAL, Raquel, ANDrade, José Miguel y López, Roberto J. (eds.): Galicia monástica. Estudos en lembranza da profesora María José Portela Silva. Santiago de Compostela, Universidad de Santiago de Compostela, 2009, pp. 245-266.

Seijas Montero, María: «La trayectoria de los monasterios cistercienses del sudoeste gallego desde la Congregación de Castilla», Cuadernos de Historia Moderna, 38 (2013), pp. 675-69I.

Silva, Maria Joao: A escrita na catedral. A Chancelaria episcopal do Porto na Idade Média. Lisboa, CITCEM, 2013.

SolAno Fernández-Sordo, Álvaro: De Maliayo a Villaviciosa. Un territorio de la marina centro-oriental de Asturias en la Edad Media. Oviedo, Fundación Cardín - Ayuntamiento de Villaviciosa - Universidad de Oviedo, 2016.

SuÁrez GonZÁlez, Ana: «Cultura escrita en Sandoval. Aproximación a la producción documental durante el abaciadgo de lohannes (II8I-I2OI)», II Congreso Internacional sobre el císter en Galicia y Portugal, II. Zamora, Montecasino, I999, pp. 40I-432.

SuÁrez GonZÁlez, Ana: «Partidos de cartularios. Una aproximación arqueológica a los ejemplares pregóticos de Oseira, Belmonte, Valparaíso y Valbuena», Cistercium, 248249 (2006), pp. 895-935.

Tock, Benoît-Michel: Scribes, souscripteurs et témoins dans les actes privés en France (VII début XII siécle). Turnhout, Brepols, 2005.

Torné Cubells, Josep: «El armarium de Valdediós», Actas del il Congreso de Bibliografía Asturiana, Ill. Oviedo, Consejería de Educación y Cultura del Principado de Asturias, I999, pp. I079-I087. 
TORNÉ Cubells, Josep: «Origen y presencia de los monjes blancos en Asturias», en VV.AA.: Monasterios cistercienses del Principado de Asturias. [Valdediós], monasterio de Valdediós, I998, pp. II-30.

VÁzquez Bertomeu, Mercedes: «Notarios y documentos en Galicia (IIoo-I40o): los monasterios cistercienses», II Congreso Internacional sobre el císter en Galicia y Portugal, II. Zamora, Montecasino, I999, pp. 995-I008.

VEYssière, Laurent: «Les archives de Clairvaux: outil de gestion du temporel», en BAUdiN, Arnaud, Dohrmann, Nicolas, y Veyssière, Laurent (dirs.): Clairvaux l'aventure cistercienne. Paris, Somogy Éditions d'art, 2015, pp. I6I-I65.

Vigil Montes, Néstor: «Los notarios del Principado de Asturias: nombramiento y actuación», en PIÑol AlabarT, Daniel (coord.): La auctoritas del notario en la sociedad medieval: nominación y prácticas. Barcelona, 2015, pp. 163-176.

ZiELINSKI, Herbert: «The trasmission of Lombard documents (to 774)», en Kosto, Adam y Winroth, Anders (eds.): Charters, cartularies and archives. Toronto, Pontifical Institute of Mediaeval Studies, 2002, pp. 33-42. 

Calidad de Revistas

Científicas Españolas

FECYT|
AÑO 2019

ISSN: 0214-9745

E-ISSN 2340-1362

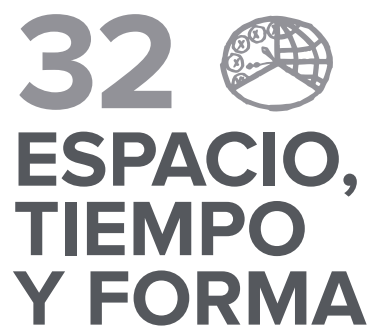

SERIE III HISTORIA MEDIEVAL

REVISTA DE LA FACULTAD DE GEOGRAFÍA E HISTORIA

\section{Artículos · Articles}

JoAquín Aparici Martí \& Concepción Villanueva Morte Deslindes y amojonamientos medievales en las serranías de Gúdar-Maestrazgo: un acercamiento al patrimonio rural y a la didáctica del territorio

\section{CARLOS BARQuero GoÑ}

Los hospitalarios y los monasterios en la Corona de Castilla durante los siglos XII y XIII

\section{Rocío BELLO GAY}

Representación política, oficios concejiles y acumulación económica en las aldeas abulenses en la Baja Edad Media: algunos apuntes acerca de la caracterización de las Ilamadas elites rurales (1474-1504)

105 Albert Cassanyes Roig Edad Media

La iglesia de Mallorca y la redención de cautivos en la Baja

133 Julián Clemente Ramos

Una dehesa por dentro: Castilrubio (1290-c. 1545). Paisaje, explotación y usurpación de términos

161 Francisco josé Díaz Marcilla

Las relaciones sociales dentro del Cancionero de Juan Alfonso de Baena (siglo XV). Redes y mentalidades

187 GUILLERMO FERnÁNDEZ ORTIZ

El archivo del monasterio cisterciense de Nuestra Señora de Belmonte (Asturias, España) en vísperas de la Reforma (1560)

\section{IVÁN GARCíA IZQUIERDO}

El linaje de Aza durante los siglos XIII y XIV: declive y resurgimiento

267 JAVIER LóPEz RÍder

Migraciones rurales en el paisaje meridional del Reino de Córdoba en el tránsito de la Edad Media a la Moderna

303 Jesús Rodríguez MoRAles \& DAVID GonzÁlez Agudo
Los caminos de la repoblación segoviana en la Transierra entre los siglos XIII y XV a partir del Privilegio de las Alberguerías de 1273

337 Jonatan Romero Pérez el siglo XIV
Estructuras militares y logísticas en la Corona de Castilla durante
379 VICENT ROYO PÉREZ

Árbitros y mediadores en el mundo rural valenciano durante la Baja Edad Media: Els Ports y El Maestrat (s. XIII-XIV)

Xosé M. SÁNCHEZ SÁNCHEZ

Aproximación al concejo de la ciudad de Santiago de Compostela y su configuración entre los siglos XIII-XV. Un poder urbano en el señorío episcopal

\subsubsection{Fernando Serrano Larráyoz \& Manuel Francisco CARRILlo Rodríguez}

Nueva perspectiva acerca de las enfermedades de Enrique IV de Castilla: el recetario del doctor Gómez García de Salamanca

\subsection{Néstor Vigil Montes}

«Tractados de pazes, aliança e concordia entre as duas coroas de Portugal e Inglaterra», un cartulario realizado a comienzos del siglo XV para consolidar el Tratado de Windsor entre los reinos de Inglaterra y Portugal (1386), la alianza permanente más prolongada de la historia

\section{Notas de Filología castellana medieval · Notes of Medieval Castilian Philology}

(9) 1 Francisco Abad Nebot

Notas bibliográfico-críticas de Filología castellana medieval

\section{Libros · Books}

515 Arsuaga Laborde, Diego, Pedro Fernández de Velasco, primer conde de Haro. Un estudio de la figura de un ricohombre en la Castilla del Cuatrocientos (CARLOS BARQUERO GOÑI)

517 BECEIRO PITA, Isabel (directora), La espiritualidad y la configuración de los reinos ibéricos (siglos XII-XV) (ENRIQUE Cantera Montenegro)

529 Galende Díaz, Juan Carlos, Ávila SeoAne, Nicolás, El rodado regio hispánico: León y Castilla antes de la unificación (1157-1230) (MAURICIO HERRERO JIMÉNEZ)

533 IrIJOA Cortés, Iago, GoICOLEA Julián, Francisco Javier, García FERNÁNDEZ, Ernesto (coords.), Mercaderes y financieros vascos y riojanos en Castilla y en Europa en el tránsito de la Edad Media a la Moderna (Ana MARÍA Rivera MEdina) 


\section{2 -}

\section{ESPACIO,}

\section{TIEMPO}

\section{Y FORMA}

UกED

SERIE III HISTORIA MEDIEVAL

REVISTA DE LA FACULTAD DE GEOGRAFÍA E HISTORIA

\section{Libros · Books}

537 LACARRA, José María, Alfonso el Batallador. Estudio preliminar de Fermín Miranda (PAULINA LóPEZ PITA)

541 Martín López, María Encarnación y CaVero Domínguez, Gregoria, Colección Documental del Monasterio de San Guillermo de Villabuena (1172-1527) (JOSÉ MIGUEL LóPEZ VILLALBA)

545 Martín Prieto, Pablo, Las Cruzadas (Margarita Cantera MONTENEGRO)

547 Rı, Alice, Legal Practice and the Written World in the Early Middle Ages. Frankish Formulae, c. 500-1000 (AlEjANDRO PABLO BAÑón PARDO)

551 RoYo PÉrez, Vicent, Les arrels històriques de la comarca dels Ports. Societat, poder i identitat en una terra de frontera durant la Baixa Edat Mitjana (JULIÁN DONADO VARA)

555 SANTIAgo Fernández, Javier de, Política monetariay moneda en el reinado de Carlos II (José Miguel López VILLALBA)

559 Santiago Fernández, Javier de y Francisco Olmos, José María. de, Corpus Inscriptionum Hispaniae Mediaevalium. Guadalajara (11121499) (José Miguel López VILLALBA)

563 Solórzano Telechea, Jesús A. y Sousa Melo, Arnaldo (eds.), ZALACAIN) Trabajar en la ciudad medieval europea (ROBERTO J. GONZÁLEZ

567 Solórzano Telechea, J.A., Haemers, J., Czaja, R. (eds.), Exclusión y disciplina social en la ciudad medieval europea (MARÍA ÁlvareZ FernánDEZ)

571 TRANChant, Mathias, Les ports maritimes de la France atlantiMARTÍN PÉREZ) que $\left(X l^{e}-X V^{e}\right.$ siècle). Volume I: Tableau géohistorique (FERNANDO 